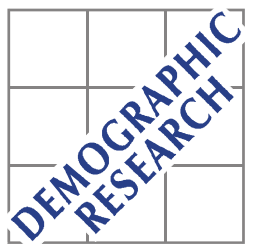

Demographic Research a free, expedited, online journal of peer-reviewed research and commentary in the population sciences published by the Max Planck Institute for Demographic Research Konrad-Zuse Str. 1, D-18057 Rostock · GERMANY www.demographic-research.org

DEMOGRAPHIC RESEARCH

VOLUME 26, ARTICLE 21, PAGES 543-592

PUBLISHED 08 JUNE 2012

http://www.demographic-research.org/Volumes/Vol26/21/

DOI: 10.4054/DemRes.2012.26.21

Research Article

The temporal dynamics of international migration in Europe: Recent trends

\author{
Jack DeWaard \\ James Raymer
}

(C) 2012 Jack DeWaard \& James Raymer.

This open-access work is published under the terms of the Creative Commons Attribution NonCommercial License 2.0 Germany, which permits use, reproduction \& distribution in any medium for non-commercial purposes, provided the original author(s) and source are given credit. See http:// creativecommons.org/licenses/by-nc/2.0/de/ 


\section{Table of Contents}

1 Introduction $\quad 544$

2 Background $\quad 545$

3 Data and methods $\quad 547$

4 Results 553

4.1 Foreign-born population stocks and migration rates 553

4.2 The expected duration of residence of international migration 557

4.2.1 Summarizing the expected duration of residence for receiving 569

4.2.2 Heterogeneity by citizenship and age $\quad 571$

$\begin{array}{lll}4.3 & \text { Summary } & 574\end{array}$

$\begin{array}{lll}5 & \text { Discussion and conclusion } & 575\end{array}$

6 Acknowledgements $\quad 576$

$\begin{array}{ll}\text { References } & 577\end{array}$

$\begin{array}{ll}\text { Appendix } & 583\end{array}$ 


\title{
The temporal dynamics of international migration in Europe: Recent trends
}

\author{
Jack DeWaard ${ }^{1}$ \\ James Raymer ${ }^{2}$
}

\begin{abstract}
Descriptive studies of international migration typically rely on measures of migrant stocks and migration rates to assess migration patterns. In this paper we propose a third alternative. Using harmonized data on age-specific migration flows between all countries in the European Union (EU) and European Free Trade Association (EFTA) each year from 2002 to 2007, we estimate the expected duration of residence of international migration, defined as the average number of years lived by migrants in the receiving country given period migration and mortality schedules. Our results provide a window into the temporal dynamics of international migration in Europe, increasingly relevant given recent expansions of the EU.
\end{abstract}

${ }^{1}$ Department of Sociology, Center for Demography and Ecology, University of Wisconsin-Madison, 8128 William H. Sewell Hall, 1180 Observatory Drive, Madison, WI 53706. E-mail: jdewaard@ssc.wisc.edu.

${ }^{2}$ University of Southampton. 


\section{Introduction}

In this paper we provide estimates of the average time lived by international migrants in each of 31 countries in the European Union (EU) and European Free Trade Association (EFTA) from 2002 to 2007. Though termed the "waiting time" of migration by Palloni (2001:265), we prefer the term, the 'expected duration of residence', ${ }^{3}$ to emphasize our attention to migration (as opposed to, but not excluding, mortality) and to distinguish the measure developed here from those typically used to summarize international migration, i.e., foreign-born population stocks and migration rates. International migration is a dynamic process characterized by variable time lived in sending and receiving countries, expectations which are largely dependent on the age-structure of migration flows. We argue that a measure summarizing these temporal dynamics at the level of sending and receiving countries should be standard fare in descriptive accounts of international migration patterns.

Few efforts have examined the temporal dynamics of international migration at the country-level. The dearth of data on duration of stay has resulted in analyses largely confined to single-country surveys (Klinthäll 2001; Reagan and Olsen 2000; Waldorf 1994; Waldorf and Esparza 1991), which are inadequate for tracking transitions between each and every pair of sending and receiving countries, and counts of persons and person-years required to take a multistate approach to his issue. ${ }^{4}$ Moreover, while published sending and receiving countries' reports of international migration flows are freely available from statistical agencies such as Eurostat, these lack a common metric across countries, preventing analysts from combining these data in any meaningful way (Kupiszewska and Nowok 2008; Poulain, Perrin and Singleton 2006).

Our efforts take advantage of recently harmonized, i.e., consistent in definition, estimates of age-specific, country-to-country migration flows for 31 countries in the EU/EFTA each year from 2002 to 2007. These were developed as part of the MIgration MOdelling for Statistical Analysis (MIMOSA) project (de Beer et al. 2010; Raymer, de Beer and van der Erf 2011), which combined both sending and receiving countries' reports of international migration flows, along with covariate information, to arrive at a consistent and complete set of estimates. These estimates represent a significant improvement relative to published sending and receiving countries' reports, which are marred by inconsistencies in data collection, measurement, and availability (Poulain, Perrin and Singleton 2006). They are also the largest harmonized data source on migration flows between countries in the world. Finally, since they are benchmarked to

\footnotetext{
${ }^{3}$ We are grateful for the comments and suggestions of Alberto Palloni and two anonymous reviewers.

${ }^{4}$ The terms "multistate" (Schoen 1988) and "multiregional" (Rogers 1975, 1995) are viewed here as synonymous. We detail the relevant mathematics of each in Section 3.
} 
a one-year timing criterion, these estimates align with the United Nations' (1998) recommendations for measuring international migration.

With mortality data, we use the MIMOSA estimates to construct period incrementdecrement life tables each year from 2002 to 2007. These track the age-specific transitions of persons via migration and death to arrive at a measure which summarizes the expected duration of residence of international migration, i.e., the average number of years lived by migrants in the receiving country given period migration and mortality schedules. A conditional life expectancy at birth, this measure summarizes the average number of years lived in the receiving country $j$ beyond age zero given prior residence in country $i$ at age zero (Willekens and Rogers 1978). Just as life expectancy at birth is often used to summarize the mortality conditions of countries with respect to the age structure of death, the expected duration of residence developed here is viewed as capturing the context of migrant reception and incorporation in receiving countries with respect to the age structure of migration and death.

\section{Background}

Descriptive studies of country-level patterns of international migration place almost exclusive reliance on measures which summarize in different ways the volume of migration. Foreign-born population stocks refer to the size or concentration of foreignborn persons relative to the total population in receiving countries, while migration rates express recent departures (emigration), arrivals (immigration), or the balance of the two (net-migration). Although each is necessary to understand international migration patterns, they are not exhaustive.

Individual-level studies have shown that the amount of time lived by migrants in receiving areas serves an integrative and to a lesser extent equalizing role where migrants' labor market and mobility outcomes are concerned (Adsera and Chiswick 2007; Redstone and Massey 2004; Borjas, Bronars and Trejo 1992). Migrants' time lived in receiving areas has likewise been linked to reductions in individual prejudice on the part of natives given more potential opportunities for constructive interpersonal contacts with foreigners (Allport 1954; Pettigrew 1998; Pettigrew and Meertens 1995; Schneider 2008; Schlueter and Scheepers 2010). For example, in his analysis of internal migration within the United States, Alexander (2005:654) noted that a "highly transient migrant stream can inhibit the development of [a] migrant community... and draw at least some sort of antipathy from both long-term settlers and other local residents alike."

The above studies raise the important issue of whether a summary measure of the temporal dynamics of international migration at the country-level might help to enhance 
understanding of migration patterns and the effects on social exclusion. Pitkin and Myers (2011:258, emphasis ours) recently argued that while many "empirical studies have yielded a multitude of specific" findings, the result has been "a plethora of disjointed and inconsistent results that yield little information about the overall [trend]." To date, the character and utility of a summary measure of the temporal dynamics of international migration that compliments stock- and rate-based measures is unknown. This is unfortunate from a migration policy perspective, where both the reception and incorporation of migrants in receiving countries is often implicit (Huddleston et al. 2011).

One possible reason for the inattention to the temporal dynamics of international migration lies in the substantial data requirements, and the fact that sending and receiving countries' reports of international migration flows are incomparable in their publicly available forms. As we detail in Section 3 of this paper, the measure for the expected duration of residence of international migration developed here is generated from dynamic population models which require a single matrix of age-specific migration flows between all pairs of sending and receiving countries each year.

Publicly available migration data in Europe consist of both emigration and immigration counts. However, when particular flows between countries are compared, these reports are frequently inconsistent (Kupiszewska and Nowok 2008:43-45). These inconsistencies arise because there is no common metric used to measure migration across countries. First, there is no consensus on what exactly constitutes a valid transition. For example, whereas migrations constitute events, migrants are persons who have undergone a change in status from non-migrant. Cross-national analyses therefore suffer from differing national viewpoints concerning exactly what or who is a migration or migrant, respectively. Second, migration is seldom measured directly, and is often inferred as a change in residence in a population register, or by comparing place of residence at two points in time. Compounding these issues is the fact that countries use different methods of data collection (Poulain, Perrin and Singleton 2006:222-227), which include administrative records, decennial population censuses, or surveys. Timing criteria likewise vary considerably across countries, and may refer to persons who plan to live or have lived in a different country for no specified period of time, three months, six months, one year, or permanently.

International migration statistics also suffer from unreliability due mainly to underregistration and data coverage (Nowok, Kupiszewska and Poulain 2006). This is often on account of the collection method or the non-participation of migrants themselves. Migration data are generally unreliable because they tend to be based on intentions. Emigration data are particularly problematic because migrants may fail to notify authorities of their movement if it is not in their interest to do so. Moreover, surveys, e.g., the United Kingdom's (UK's) International Passenger Survey, typically do not 
have large enough sample sizes to capture the level of detail required to analyze country-to-country migration flows without severe irregularities in the data. In some instances reported flows for certain countries may be missing for particular years or altogether. Migration data may also be available only for the total population and not for more detailed demographic, socioeconomic, or spatially disaggregated subgroups required for targeted studies.

Because of these problems only limited work has been carried out in the area of estimating international migration flow matrices. There is, however, at least one major exception that focuses on European migration. The estimates produced by the MIMOSA project, as described in de Beer et al. (2010) and Raymer, de Beer and van der Erf (2011), represent the first set of flows that are truly amenable to cross-national comparison at a relatively large scale. ${ }^{5}$ We use these harmonized estimates of international migrant stocks and migration flows for 31 countries in the EU/EFTA each year from 2002 to 2007 in the current project.

\section{Data and methods}

We use multistate methods (Rogers 1975, 1995; Schoen 1988) to construct period increment-decrement life tables which track the age-specific transitions of international migrants from and to 31 countries in the EU/EFTA, a residual "rest of the world" category, and to death each year from 2002 to 2007. The state-space is thus comprised of 33 states and is exhaustive. ${ }^{6}$ The total number of transitions analyzed in this project is thus $114,048 .^{7}$

Data requirements include, for each year, age-specific country-to-country transition rates. As stated in the introduction, we use harmonized estimates of agespecific country-to-country migration flows from and to all countries in the EU/EFTA (including from and to the rest of the world) each year from 2002 to 2007, obtained from the MIMOSA project. The methodology used to produce these estimates is described in de Beer et al. (2010) and Raymer, de Beer and van der Erf (2011), and the estimates themselves are available at the Netherlands Interdisciplinary Demographic Institute's website. ${ }^{8}$ Based on a hierarchical procedure, available country-to-country migration flow data were harmonized using the reports of sending and receiving

\footnotetext{
${ }^{5}$ Another example currently in progress is the Integrated Modeling of European Migration (IMEM) project (Raymer et al. 2010).

${ }^{6}$ The term state refers to any of the 31 EU/EFTA countries, the "rest of the world" as a single entity, or death.

${ }^{7}$ We track 1,056 transitions between 32 sending states (not including death) and 33 receiving states (including death, which is absorbing) for 18, five-year age groups each year from 2002 to 2007, totaling 1,056 $* 18 * 6=114,048$ possible transitions.

${ }^{8}$ Available at http://www.knaw.nl/Pages/NID/24/928.bGFuZz1VSw.html.
} 
countries following an extension of Poulain's (1993, 1999) optimization procedure. Missing marginal and origin-destination associations were then estimated using a multiplicative component approach and incorporating covariate information. The estimated origin-destination-specific flows were then disaggregated by age and sex based on patterns exhibited by countries with available data.

With respect to the remaining data requirements, the MIMOSA project also provides harmonized age-specific population counts for each year (Kupiszewska, Wiśniowski and Bijak 2009). Annual population counts for the rest of the world were obtained by subtracting the former counts for countries in the EU/EFTA from agespecific estimates of the global population for each year obtained from the U.S. Census' International Database (IDB). Annual age-specific death counts were obtained for EU/EFTA countries from Eurostat's New Cronos database and, for the rest of the world, by subtracting the former counts for EU/EFTA countries from the number of deaths estimated for each year from global model life tables available from the World Health Organization (WHO) ${ }^{9}$

Our conceptual model is presented in Figure 1. The state-space depicted is a firstorder Markov process where, for country $i, q^{i j}$ and $q^{j i}$ represent country-to-country transition probabilities at each age, and $q^{i d}$ and $q^{j d}$ represent the force of mortality (Palloni 2001; Rogers 1975, 1995; Schoen 1988).

\section{Figure 1: Model of states and transitions}

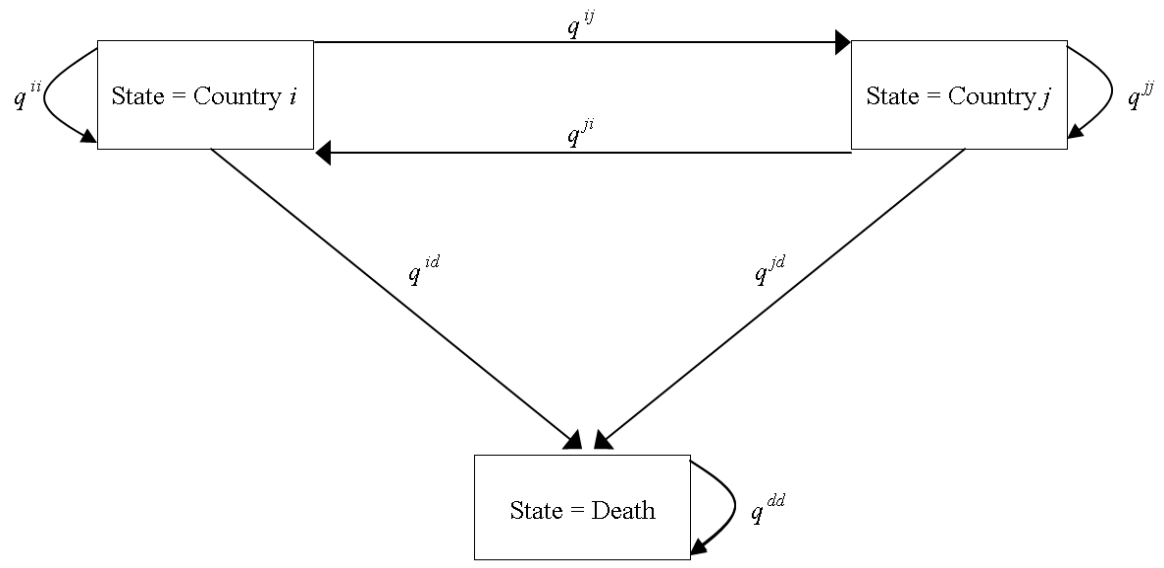

${ }^{9}$ Given that global model life tables from the WHO are available for 2000 and 2008, we linearly interpolate age-specific death rates for each year from 2002 to 2007, and combine these with age-specific estimates of the global population obtained from the U.S. Census' IDB to calculate age-specific death counts for each year. 
Toward estimating each of the probabilities in Figure 1, the starting point for constructing increment-decrement life tables is to assemble age-specific transition matrices of migration rates, M(x), each year (Palloni 2001; Schoen 1988). For a system comprised of $k$ countries, these matrices take the form: ${ }^{10}$

$$
\boldsymbol{M}(x)=\left[\begin{array}{ccccc}
\sum_{j}{ }_{n} M_{x}^{1 j} & -{ }_{n} M_{x}^{12} & \cdots & -{ }_{n} M_{x}^{1 k} & -{ }_{n} M_{x}^{1 d} \\
-{ }_{n} M_{x}^{21} & \sum_{j}{ }_{n} M_{x}^{2 j} & \ldots & -{ }_{n} M_{x}^{2 k} & -{ }_{n} M_{x}^{2 d} \\
\vdots & \vdots & \ddots & \vdots & \vdots \\
-{ }_{n} M_{x}^{k 1} & -{ }_{n} M_{x}^{k 2} & \ldots & \sum_{j}{ }_{n} M_{x}^{k j} & -{ }_{n} M_{x}^{k d} \\
0 & 0 & \cdots & 0 & 0
\end{array}\right]
$$

Excluding the last row and column, each of the rows and columns in (1) represent sending and receiving countries, respectively. The off-diagonal elements are the rates of emigration from each country $i$ to $j$ between ages $x$ and $x+n$, multiplied by negative one. Each diagonal element represents the sum of the emigration rates from country $i$ to any and all receiving countries $(j=1,2, \ldots, k$ for $i \neq j)$ and death. Transitions from and to death are accommodated by setting the elements in the last row to zero, and those in the last column to the age-specific death rate in the sending country, $-{ }_{n} M_{x}^{i d}(i=1,2, \ldots$, $k)$.

Life table construction is carried out by converting each of the rates in (1) into probabilities and tracking age-specific transitions at each age. With occurrenceexposure rates this can be done using Schoen's (1988) general algorithm or, alternatively, Rogers' (1995:96) “Option 1" method (Rogers and Ledent 1976), each with the assumption that the transitions from country $i$ to $j$ are linear in the age interval $x$ to $x+n$ (Palloni 2001):

$$
\mathbf{I}(x+n)=\mathbf{I}(x)[\mathbf{I}-2.5 \mathbf{M}(x)][\mathbf{I}+2.5 \mathbf{M}(x)]^{-1}
$$

${ }^{10}$ Noting that sending and receiving countries represent columns and rows, respectively, the equivalent notation in Rogers (1995:96; see also Rogers and Ledent 1976), where deaths are embedded along the main diagonal, is:

$$
\mathbf{M}(x)=\left[\begin{array}{cccc}
{ }_{n} M_{x}^{1 d}+\sum_{j}{ }_{n} M_{x}^{1 j} & -{ }_{n} M_{x}^{21} & \cdots & -{ }_{n} M_{x}^{k 1} \\
-{ }_{n} M_{x}^{12} & { }_{n} M_{x}^{2 d}+\sum_{j}{ }_{n} M_{x}^{2 j} & \ldots & -{ }_{n} M_{x}^{k 2} \\
\vdots & \vdots & \ddots & \vdots \\
-{ }_{n} M_{x}^{1 k} & -{ }_{n} M_{x}^{2 k} & \cdots & { }_{n} M_{x}^{k d}+\sum_{j}{ }_{n} M_{x}^{k j}
\end{array}\right]
$$


The $\mathbf{l}(x+n)$ matrix contains counts of migrants and non-migrants at the end of the age interval $x$ to $x+n$. The off-diagonal elements are counts of completed transitions from country $i$ to $j$, while the diagonal elements are counts of those who did not migrate. The $\mathbf{l}(x)$ matrix contains along the main diagonal, with zeros in the offdiagonal elements, the number of survivors at age $x$. At age zero these values represent the size of the hypothetical birth cohort in each country. Here, to minimize the potentially distorting impact of population size across countries (Herting et al. 1997), these values are set equal, as is convention in the literature (Preston, Heuveline and Guillot 2001; Rogers 1995). ${ }^{11}$ Lastly, $\mathbf{I}$ is an identity matrix, while the $\mathbf{M}(x)$ matrix is the same as that discussed above. Summing each column in the $\mathbf{I}(x+n)$ matrix and arranging these totals along the main diagonal, with zeros in the off-diagonal elements, yields the $\mathbf{I}(y)$ matrix (not shown). ${ }^{12}$ In the subsequent age interval this matrix then takes the place of the $\mathbf{l}(x)$ matrix to repeat the calculation in (2) until each age interval is exhausted. This iterative process yields a set of components which can then be assembled into a multistate life table.

Because the MIMOSA data are available in five-year age intervals for single calendar years from 2002 to 2007, it is necessary to transform the rates in (1) at the outset so that these reflect the probability of transition over five years, ${ }_{5} q_{x}^{i j}$. This is achieved with the following transformation, derived from the probability of not making a transition in a single year, raised to the power of five: ${ }^{13}$

$$
{ }_{5} q_{x}^{i j}=1-\left[1-\left(\frac{{ }_{5} M_{x}^{i j}}{1+0.5_{5} M_{x}^{i j}}\right)\right]^{5}
$$

Working directly with the probabilities derived in (3), equation (2) reduces to:

$$
\mathbf{l}(x+n)=\mathbf{l}(x) \mathbf{Q}(x)
$$

where $\mathbf{Q}(x)$ is a matrix of age-specific transition probabilities, wherein each row is a probability vector, arranged in exactly the same way as the migration rates in (1).

Constructing period increment-decrement life tables is a cumbersome though not intrinsically difficult task. A primary innovation in this project is the number of states $(n=33)$ considered to comprise the state-space. Multistate demographic programs, e.g., SPACE (Rogers 1995; see also Willekens and Rogers 1978), are available and user

\footnotetext{
${ }^{11}$ All radixes are set to 100,000 .

${ }^{12}$ See Schoen (1988) and Palloni (2001). Rogers' (1975, 1995; see also Rogers and Ledent 1976) method achieves the same result, but tracks transitions from country $i$ to $j$ using the columns of the $\mathbf{l}(x+n)$ matrix, thereby requiring summation across the rows to generate the $\mathbf{l}(y)$ matrix.

${ }^{13} \mathrm{We}$ are grateful for the assistance of Jenna Nobles and Nico Keilman with this conversion.
} 
friendly; however, the maximum number of states is limited to four. While other options are available without these restrictions, e.g., a $\mathrm{C}++$ program developed by Tiemeyer and Ulmer (1991) and, more recently, LIPRO developed by van Imhoff and Keilman (1991; see also van Imhoff 2005 and Willekens 2011), we followed Palloni's suggestion (2001:272) and developed a routine for increment-decrement life table construction using the Stata statistical software package. This provided greater control in implementing the above solutions and estimating the key quantities of interest in this project detailed below.

The key quantities of interest in this project are a set of period, conditional life expectancies at birth:

$$
e_{0}^{i j}=\frac{T_{0}^{i j}}{l_{0}^{i}}
$$

where $T_{0}^{i j}$ is the total number of person-years lived in country $j$ above age zero by those with prior residence in country $i$ at exact age zero, and $l_{0}^{i}$ is the size of the hypothetical birth cohort in country $i$ at exact age zero (Willekens and Rogers 1978). When $i \neq j$, this quantity summarizes the "waiting time" of international migration for each and every pair of sending and receiving countries (Palloni 2001:265). Alternatively, when $i=j$, this quantity expresses these dynamics for non-movers. As mentioned earlier, we refer to the quantity in (5) as the expected duration of residence, to stress the contribution of migration to their construction and interpretation. It is important to recognize that this measure summarizes the cumulative effects of age-specific, country-to-country migration, including both emigration and immigration. Although the data are unavailable for international migration, it would be preferable to further condition on country of birth (Ledent 1981; Philipov and Rogers 1981; Rogers and Belanger 1990; Rogers and Raymer 2005).

The above quantities are standard in the multistate literature (see Palloni 2001; Rogers 1975, 1995; Schoen 1988), where one conditions on a single sending country, one at a time, and then estimates the average years that a person could be expected to live in each and every receiving country. From the perspective of the receiving country, this means that a set of measures, one for each sending country $i(i=1,2, \ldots, k$ for $i \neq j)$, describe the temporal dynamics of international migration. However, to obtain a single summary measure for each receiving country that can be compared against more commonly used measures of international migration, e.g., foreign-born population stocks and migration rates, the quantity in (5) requires conditioning on any and all sending countries (for $i \neq j$ ). In this way, one can obtain information about the average number of years that a person from any sending country (or from some defined set of 
sending countries) could be expected to live in the receiving country above age zero, denoted by $\bar{e}_{0}^{* j}$ :

$$
\bar{e}_{0}^{* j}=\sum_{i=1}^{k} e_{0}^{i j} w_{0}^{i j}, \quad i \neq j,
$$

where

$$
w_{0}^{i j}=\frac{n^{i j}}{\sum_{i=1}^{k} n^{i j}}, \quad i \neq j .
$$

Note, $n^{i j}$ denotes total migration (counts) from country $i$ to $j$. If one were to arrange each of the quantities in (5) into a matrix, where each element is the expected duration of residence lived in country $j$ beyond age zero by persons previously residing in country $i$ at exact age zero, then it is clear that the quantity in (6) is just a weighted average of expected durations of residence across all sending countries $(i=1,2, \ldots, k$ for $i \neq j$ ) for each receiving country. Although taking the perspective of the receiving country is not standard in the multistate literature (Palloni 2001), these relationships are nonetheless embedded in the mechanics of multistate life tables. ${ }^{14}$ We further wish to consider the very different likelihoods and sizes of migration to each receiving country, $w_{0}^{i j}$, which vary substantially depending on the sending country. The quantity in (6) thus accounts for the relative size of migration from each sending country and thereby provides an average picture of the temporal dynamics of international migration by taking into account the migration linkages shared by specific pairs of sending and

${ }^{14}$ Let the superscript $\ulcorner j$ denote any country but $j$. The expected duration of residence in country $j$ for persons from any sending country but $j$ is then:

$$
e_{0}^{-j j}=\frac{T_{0}^{-j j}}{l_{0}^{\neg j}}=\frac{\sum_{i=1}^{k} T_{0}^{i j}}{\sum_{i=1}^{k} l_{0}^{i}}, \quad i \neq j
$$

When $l_{0}^{i}$ is constant across sending countries, equation (8) simplifies to an average of the expected durations of residence across all sending countries.

$e_{0}^{-j j}=\frac{1}{k} \sum_{i=1}^{k} \frac{T_{0}^{i j}}{l_{0}^{i}}, i \neq j$

For ease of notation and because we apply weights after the fact, we adopt the notation in equation (6) to denote that the expected duration of residence is a weighted average for the reasons discussed above. Nonetheless, we detail equations (8) and (9) to demonstrate that there is nothing inherent in the mechanics of multistate life tables which prohibits one from taking the perspective of the receiving country. 
receiving countries. To illustrate, according to the 2007 MIMOSA estimates, over $75 \%$ of migration from countries in the EU/EFTA to the Czech Republic originated in Slovakia. Without the weights, the impact of this important migration exchange would be underrepresented.

\section{Results}

\subsection{Foreign-born population stocks and migration rates}

We begin this section by summarizing two measures of international migration, foreignborn population stocks and migration rates, for 31 countries in the EU/EFTA from 2002 to 2007. Since much descriptive work on international migration relies extensively on these measures, our consideration of them here provides a point of comparison and departure in the current paper.

Foreign-born population stocks are presented in Table 1. These were estimated as part of the MIMOSA project (Kupiszewska, Wiśniowski and Bijak 2009). As one might expect, the core immigrant receiving countries in Northern, Western, and Southern Europe have sizeable concentrations of migrants (Castles and Miller 2003). For example, Lichtenstein, Luxembourg, and Switzerland exhibit the largest percentages of foreign-born population stocks at $37 \%, 34 \%$ and $22 \%$, respectively, in 2007. In total, 16 countries in 2007 had foreign-born populations greater than $10 \%$ of the total population, including three of the five largest countries in Europe, i.e., France, Germany, and Spain. The countries with the smallest percentages were mostly new EU accession countries, including Bulgaria, Romania, Poland, and Hungary. With a few exceptions, foreignborn population stocks increased from 2002 to 2007. The most sizeable increases over the period were in Spain $(+5.36$ percentage points), Ireland $(+3.56)$, Iceland $(+3.48)$ and Italy (+2.19). In contrast, the largest declines were in Latvia (-1.93) and Estonia (-1.73). Overall, the picture is one of increasing concentrations of foreign-born persons over the period, excluding some of the new EU accession countries in Central and Eastern Europe. 
DeWaard \& Raymer: The temporal dynamics of international migration in Europe

Table 1: Foreign-born population stocks as a percent of the total population in 31 EU/EFTA countries, 2002-2007

\begin{tabular}{|c|c|c|c|c|c|c|c|}
\hline \multicolumn{2}{|c|}{ Country } & \multirow{2}{*}{$\begin{array}{r}\mathbf{2 0 0 2} \\
12.75\end{array}$} & \multirow{2}{*}{$\begin{array}{r}\mathbf{2 0 0 3} \\
13.17\end{array}$} & \multirow{2}{*}{$\begin{array}{r}\mathbf{2 0 0 4} \\
13.57\end{array}$} & \multirow{2}{*}{$\begin{array}{r}\mathbf{2 0 0 5} \\
13.98\end{array}$} & \multirow{2}{*}{$\begin{array}{r}\mathbf{2 0 0 6} \\
14.38\end{array}$} & \multirow{2}{*}{$\begin{array}{r}\mathbf{2 0 0 7} \\
14.80\end{array}$} \\
\hline AT- & Austria & & & & & & \\
\hline BE- & Belgium & 10.79 & 11.12 & 11.40 & 11.68 & 12.07 & 12.51 \\
\hline BG- & Bulgaria & 0.55 & 0.55 & 0.54 & 0.54 & 0.53 & 0.53 \\
\hline $\mathrm{CH}-$ & Switzerland & 21.42 & 21.59 & 21.75 & 21.90 & 22.04 & 22.19 \\
\hline CY- & Cyprus & 12.81 & 13.06 & 13.34 & 13.63 & 13.90 & 14.12 \\
\hline$C Z-$ & Czech Republic & 4.47 & 4.45 & 4.43 & 4.42 & 4.40 & 4.38 \\
\hline DE- & Germany & 12.81 & 12.89 & 12.71 & 12.84 & 12.85 & 12.84 \\
\hline DK- & Denmark & 7.29 & 7.47 & 7.59 & 7.69 & 7.84 & 8.04 \\
\hline EE- & Estonia & 17.98 & 17.65 & 17.31 & 16.97 & 16.62 & 16.25 \\
\hline ES- & Spain & 6.20 & 7.73 & 8.55 & 9.90 & 11.26 & 11.56 \\
\hline $\mathrm{Fl}-$ & Finland & 2.79 & 2.92 & 3.04 & 3.18 & 3.36 & 3.56 \\
\hline FR- & France & 10.36 & 10.53 & 10.70 & 10.85 & 10.85 & 10.85 \\
\hline GR- & Greece & 10.36 & 10.47 & 10.58 & 10.68 & 10.79 & 10.89 \\
\hline HU- & Hungary & 2.82 & 2.77 & 2.72 & 2.68 & 2.63 & 2.58 \\
\hline IE- & Ireland & 10.37 & 9.10 & 8.91 & 9.88 & 14.67 & 13.93 \\
\hline IS- & Iceland & 6.40 & 6.61 & 6.72 & 7.04 & 8.23 & 9.88 \\
\hline IT- & Italy & 4.02 & 4.46 & 4.91 & 5.35 & 5.78 & 6.21 \\
\hline LI- & Liechtenstein & 38.81 & 38.43 & 38.03 & 37.68 & 37.31 & 36.93 \\
\hline LT- & Lithuania & 6.10 & 6.36 & 6.89 & 6.61 & 6.61 & 6.56 \\
\hline LU- & Luxembourg & 32.72 & 33.03 & 33.35 & 33.64 & 33.96 & 34.27 \\
\hline LV- & Latvia & 18.04 & 17.24 & 16.96 & 16.65 & 16.34 & 16.11 \\
\hline MT- & Malta & 5.55 & 5.69 & 5.83 & 5.96 & 6.06 & 6.04 \\
\hline NL- & Netherlands & 10.40 & 10.59 & 10.65 & 10.65 & 10.62 & 10.59 \\
\hline NO- & Norway & 6.96 & 7.33 & 7.59 & 7.84 & 8.20 & 8.65 \\
\hline PL- & Poland & 2.08 & 2.01 & 1.94 & 1.88 & 1.81 & 1.75 \\
\hline PT- & Portugal & 6.40 & 6.53 & 6.66 & 6.78 & 6.89 & 7.00 \\
\hline RO- & Romania & 0.61 & 0.62 & 0.62 & 0.62 & 0.63 & 0.64 \\
\hline SE- & Sweden & 11.54 & 11.78 & 12.01 & 12.21 & 12.44 & 12.90 \\
\hline SI- & Slovenia & 10.89 & 10.92 & 11.00 & 10.87 & 11.10 & 11.31 \\
\hline SK- & Slovakia & 2.83 & 3.49 & 4.14 & 4.05 & 4.15 & 4.31 \\
\hline UK- & United Kingdom & 8.40 & 8.50 & 8.83 & 9.26 & 9.96 & 9.97 \\
\hline
\end{tabular}

Source: Kupiszewska et al. (2009) 
Foreign-born population stocks obscure the distinction between past and recent migrants. To isolate more recent trends we present the estimated rates of immigration and emigration from 2002 to 2007 for the same set of 31 countries in the EU/EFTA. As in Table 1, the flows used to construct these rates were obtained from reports produced by the MIMOSA project (de Beer et al. 2010; Raymer, de Beer and van der Erf 2011). In Table 2 we see that there is a large amount of heterogeneity in the estimated rates of immigration and emigration, though the patterns appear to be relatively stable over time. The highest rates tend to be associated with small countries such as Cyprus and Luxembourg, with a few exceptions such as the immigration rates for Slovenia and Estonia.

Consistent with Table 1, a clear trend emerges in positive net migration among key destination countries in Northern, Western, and Southern Europe. In contrast, among Central and Eastern European countries the trends are predominantly negative. The largest gains in the rate of net migration over the period were concentrated in the Czech Republic $(+16.51$ per thousand), Iceland $(+9.39)$, Liechtenstein $(+5.96)$, and Norway $(+3.85)$. These trends are largely consistent with EU expansions in 2004 and 2007. For example, Poland's emigration rate steadily increased from 6.2 per thousand in 2003 to 10.9 per thousand in 2006. We also see that during the same time the UK's immigration rate increased from 8.0 per thousand in 2003 to 9.6 per thousand in 2006. Both Poland's emigration rate and the UK's immigration rate decreased slightly in 2007, suggesting a slowing down in movements. The corresponding immigration rates for Germany, a country that restricted new EU accession movements, did not increase during this time. 
DeWaard \& Raymer: The temporal dynamics of international migration in Europe

Table 2: Immigration and emigration rates (per 000) to/from 31 EU/EFTA countries, 2002-2007

\begin{tabular}{|c|c|c|c|c|c|c|c|c|c|c|c|c|c|}
\hline \multirow{2}{*}{\multicolumn{2}{|c|}{ Country }} & \multicolumn{6}{|c|}{ Immigration } & \multicolumn{6}{|c|}{ Emigration } \\
\hline & & \multirow{2}{*}{$\begin{array}{c}2002 \\
11.76\end{array}$} & \multirow{2}{*}{$\frac{2003}{13.06}$} & \multirow{2}{*}{$\frac{2004}{15.19}$} & \multirow{2}{*}{$\frac{2005}{15.25}$} & \multirow{2}{*}{$\begin{array}{c}2006 \\
12.93\end{array}$} & \multirow{2}{*}{$\frac{2007}{13.96}$} & \multirow{2}{*}{$\frac{2002}{5.90}$} & \multirow{2}{*}{$\frac{2003}{7.06}$} & \multirow{2}{*}{$\frac{2004}{7.65}$} & \multirow{2}{*}{$\frac{2005}{8.26}$} & \multirow{2}{*}{$\frac{2006}{9.43}$} & \multirow{2}{*}{$\frac{2007}{9.73}$} \\
\hline AT- & Austria & & & & & & & & & & & & \\
\hline BE- & Belgium & 7.15 & 7.39 & 7.96 & 8.66 & 10.04 & 10.73 & 4.59 & 4.80 & 5.04 & 5.30 & 5.84 & 6.15 \\
\hline BG- & Bulgaria & 3.47 & 3.78 & 4.02 & 4.00 & 4.28 & 4.58 & 6.54 & 7.74 & 7.89 & 7.82 & 8.65 & 11.54 \\
\hline $\mathrm{CH}-$ & Switzerland & 17.34 & 16.34 & 16.28 & 15.91 & 17.07 & 22.02 & 10.77 & 10.46 & 10.79 & 11.03 & 11.79 & 11.97 \\
\hline CY- & Cyprus & 16.40 & 18.94 & 24.41 & 26.44 & 16.35 & 19.74 & 46.96 & 29.33 & 39.79 & 58.99 & 41.27 & 64.53 \\
\hline CZ- & $\begin{array}{l}\text { Czech } \\
\text { Republic }\end{array}$ & 8.47 & 11.38 & 10.13 & 11.42 & 12.87 & 19.65 & 18.34 & 19.31 & 20.00 & 15.02 & 20.11 & 13.01 \\
\hline DE- & Germany & 8.20 & 7.36 & 7.22 & 6.80 & 6.38 & 6.64 & 4.89 & 4.92 & 5.46 & 5.24 & 5.42 & 6.05 \\
\hline DK- & Denmark & 6.82 & 6.53 & 6.55 & 6.86 & 7.41 & 8.44 & 5.28 & 5.33 & 5.63 & 5.76 & 6.08 & 5.78 \\
\hline EE- & Estonia & 2.92 & 2.53 & 3.46 & 3.20 & 3.52 & 3.53 & 6.57 & 6.48 & 7.32 & 7.53 & 8.36 & 8.77 \\
\hline ES- & Spain & 7.31 & 9.99 & 10.02 & 10.35 & 11.90 & 13.33 & 2.64 & 3.88 & 3.48 & 3.98 & 7.21 & 10.85 \\
\hline $\mathrm{Fl}-$ & Finland & 4.08 & 4.00 & 4.55 & 4.80 & 5.01 & 5.80 & 2.73 & 2.57 & 2.85 & 2.63 & 2.62 & 2.71 \\
\hline FR- & France & 4.11 & 4.18 & 4.47 & 4.79 & 5.66 & 6.05 & 2.56 & 2.69 & 2.88 & 3.08 & 3.44 & 3.61 \\
\hline GR- & Greece & 5.54 & 5.38 & 5.69 & 5.83 & 5.99 & 6.14 & 3.57 & 3.38 & 3.42 & 3.46 & 3.43 & 3.59 \\
\hline HU- & Hungary & 3.76 & 3.76 & 4.09 & 4.24 & 4.53 & 4.72 & 5.23 & 5.23 & 5.88 & 6.48 & 7.07 & 7.56 \\
\hline IE- & Ireland & 11.13 & 11.02 & 11.48 & 12.93 & 16.89 & 15.66 & 6.69 & 6.92 & 7.73 & 8.16 & 9.23 & 9.95 \\
\hline IS- & Iceland & 8.15 & 10.58 & 13.00 & 15.38 & 17.51 & 19.46 & 12.64 & 12.09 & 12.93 & 12.79 & 13.45 & 14.56 \\
\hline IT- & Italy & 5.69 & 11.49 & 10.68 & 7.79 & 8.73 & 8.67 & 2.10 & 2.24 & 2.10 & 2.16 & 2.11 & 2.22 \\
\hline LI- & Liechtenstein & 5.73 & 4.46 & 6.50 & 5.92 & 11.26 & 13.68 & 6.68 & 5.85 & 8.25 & 7.69 & 7.82 & 8.67 \\
\hline LT- & Lithuania & 3.12 & 2.88 & 3.34 & 4.20 & 4.83 & 5.39 & 5.74 & 7.14 & 8.39 & 8.74 & 8.20 & 8.70 \\
\hline LU- & Luxembourg & 37.14 & 38.26 & 38.21 & 39.47 & 33.57 & 35.56 & 22.03 & 23.61 & 23.86 & 25.29 & 23.10 & 25.70 \\
\hline LV- & Latvia & 1.61 & 1.55 & 1.91 & 2.19 & 3.30 & 4.22 & 7.73 & 5.88 & 6.88 & 6.25 & 11.03 & 9.02 \\
\hline MT- & Malta & 5.61 & 5.69 & 5.31 & 6.26 & 6.29 & 7.00 & 8.59 & 8.90 & 9.35 & 9.50 & 10.83 & 10.60 \\
\hline NL- & Netherlands & 7.85 & 6.73 & 6.06 & 5.93 & 6.49 & 7.48 & 4.43 & 4.58 & 4.95 & 5.44 & 5.87 & 6.02 \\
\hline NO- & Norway & 7.16 & 6.35 & 6.40 & 6.95 & 7.90 & 10.61 & 4.95 & 4.90 & 4.66 & 4.40 & 4.58 & 4.55 \\
\hline PL- & Poland & 2.82 & 3.01 & 4.07 & 4.01 & 4.63 & 6.43 & 6.00 & 6.16 & 7.18 & 8.06 & 10.91 & 9.89 \\
\hline PT- & Portugal & 4.44 & 4.48 & 4.69 & 4.95 & 5.68 & 6.02 & 4.04 & 4.25 & 4.39 & 4.49 & 4.95 & 5.32 \\
\hline RO- & Romania & 2.86 & 3.17 & 3.29 & 3.52 & 4.00 & 4.63 & 8.57 & 13.27 & 12.84 & 12.01 & 13.53 & 15.14 \\
\hline SE- & Sweden & 7.16 & 7.06 & 6.85 & 7.18 & 10.53 & 10.87 & 3.66 & 3.86 & 4.09 & 4.29 & 4.76 & 4.86 \\
\hline SI- & Slovenia & 3.50 & 2.87 & 3.51 & 3.65 & 3.42 & 3.58 & 2.85 & 2.61 & 2.93 & 2.63 & 2.78 & 3.30 \\
\hline SK- & Slovakia & 2.94 & 3.31 & 5.70 & 12.06 & 16.15 & 11.01 & 9.86 & 10.62 & 11.57 & 14.57 & 15.70 & 15.98 \\
\hline UK- & $\begin{array}{l}\text { United } \\
\text { Kingdom }\end{array}$ & 7.16 & 7.95 & 9.52 & 9.07 & 9.60 & 9.49 & 4.58 & 4.75 & 4.72 & 4.94 & 5.50 & 5.08 \\
\hline
\end{tabular}

Source: Kupiszewska et al. (2009), Raymer et al. (2011) 


\subsection{The expected duration of residence of international migration}

The above results generate little in the way of new findings. Northern, Western, and Southern Europe continue to experience unprecedented volumes of international migration into the twenty-first century (Castles 2007). What is not understood to date is whether rising volumes of international migration necessarily translate into longer and thus more permanent migrations, or whether international migrants are simply turning over at rates consistent with the figures in Tables 1 and 2.

To address this issue, in Table 3 we present a matrix containing the expected durations of residence for each pair of sending and receiving countries in $2007 .{ }^{15}$ When summed across each row, these quantities equal total life expectancy at age zero in the sending country, $e_{0}^{i *}$. Each of the diagonal elements, $e_{0}^{i i}$, represent the average number of years that a person can expect to live beyond age zero in their country of residence at age zero; and the off-diagonal elements, $e_{0}^{i j}$, represent the average number of years a person can expect to live in another country $j$ above age zero provided they resided in country $i$ at age zero (for $i \neq j$ ). ${ }^{16}$ Note, as stated earlier, that these figures are based on previous/next country of residence and do not take into account country of birth due to data limitations.

Given the age-specific migration and mortality observed in 2007, persons living in Austria at age zero, for example, could expect to live an average of 75.9 years beyond age zero, of which 51.5 years could be expected to be lived in Austria, 3.7 years in Germany, 8.7 years in other EU/EFTA countries, and 12.0 years outside the EU/EFTA system. By comparison, persons living in Iceland could expect to live an average of 76.6 years above age zero, of which only 39.3 years could be expected to be lived in Iceland. The remaining 37.3 years are divided among 15.8 years in other Scandinavian countries (Denmark, Norway, and Sweden), 3.7 years in the UK, 8.1 years in other EU/EFTA countries, and 9.7 years outside the EU/EFTA system. It is important to note that the quantities in Table 3 should be interpreted as the average number of years for the population across the life course, and not as actual durations of stay for individuals who, in order to be counted as migrants in the estimated data, would have had to stay for at least one year in the country of destination.

The information contained in Table 3 is a valuable source of information on the effects of age- and origin-destination-specific migration. For example, we see that persons living in Norway at age zero can expect to spend, on average, 3.2 years in Sweden. Persons living in Sweden at age zero, on the other hand, can expect to spend

\footnotetext{
${ }^{15}$ These figures are provided for the years 2002-2006 in Appendices 1-3.

${ }^{16} \mathrm{Had}$ we adopted the mechanics of Rogers $(1975,1995)$, the figures displayed in Table 3 and in Appendices 1-3 would be the same, but merely transposed.
} 
only 1.9 years in Norway. For flows between the Czech Republic and Slovakia, these differences are even more striking. Persons living in Slovakia at age zero can expect to spend 11.0 years in the Czech Republic, on average, whereas persons living in the Czech Republic at age zero can only expect to spend 1.4 years in Slovakia. In other cases the differences are not as striking. For example, the number of years that persons living in Belgium at age zero can expect to live in the Netherlands is roughly the same as for persons in the Netherlands at age zero living in Belgium, about two years on average.

The expected durations of residence in Table 3 can also be used to indicate the retention or "holding power" of countries (Herting, Grusky and Van Rompaey 1997:268). In Table 4 we show the average number of years lived above age zero in country $i$ by those residing in $i$ at age zero each year from 2002 to 2007. Countries are ordered according to the percentage of total life in 2007 lived above age zero in the same country of residence as at age zero. At the top of the list is the "Rest of World" category where, in 2007, persons outside the EU/EFTA system could expect to spend 58.4 years out of a total of 59.2 years (or 98.5\%) in this region. The next five countries are Italy $(90.9 \%)$, Finland $(87.2 \%)$, Slovenia (86.9\%), France $(85.6 \%)$ and Greece $(85.3 \%)$. At the bottom of the list are Cyprus $(20.6 \%)^{17}$, Luxembourg (38.7\%), Iceland (51.4\%), Slovakia (57.6\%) and Switzerland (58.9\%). In general, persons living in the countries listed in the top half of Table 4 can expect to spend over two-thirds of their lives above age zero in their country of residence at age zero. In the bottom half of the table these expectations are between one-half and two-thirds, excluding Luxembourg and Cyprus.

\footnotetext{
${ }^{17}$ Note, the expectations for Cyprus are particularly low and could reflect an error in the MIMOSA estimates, e.g., the estimated emigration counts may be too large.
} 
Table 3: Expected duration of residence (in years) to be lived by a person in receiving country $j$ above age zero given prior residence in country $i$ at age zero: EU/EFTA countries and rest of world, 2007

\begin{tabular}{|c|c|c|c|c|c|c|c|c|c|c|c|c|c|}
\hline \multirow{2}{*}{$\begin{array}{l}\text { Sending } \\
\text { Country } i\end{array}$} & \multicolumn{13}{|c|}{ Receiving Country $j$} \\
\hline & AT & BE & BG & $\mathrm{CH}$ & CY & $C Z$ & DE & DK & EE & ES & FI & FR & GR \\
\hline AT- Austria & 51.51 & 0.12 & 0.31 & 1.03 & 0.01 & 0.32 & 3.69 & 0.10 & 0.01 & 0.43 & 0.06 & 0.42 & 0.17 \\
\hline BE- Belgium & 0.11 & 58.03 & 0.03 & 0.19 & 0.00 & 0.06 & 1.07 & 0.12 & 0.00 & 0.82 & 0.09 & 3.01 & 0.09 \\
\hline BG- Bulgaria & 0.74 & 0.18 & 43.85 & 0.24 & 0.05 & 0.61 & 4.76 & 0.10 & 0.00 & 4.87 & 0.07 & 0.63 & 0.44 \\
\hline $\mathrm{CH}$ - Switzerland & 0.78 & 0.25 & 0.07 & 45.41 & 0.01 & 0.19 & 4.60 & 0.26 & 0.01 & 2.09 & 0.21 & 3.72 & 0.18 \\
\hline CY- Cyprus & 0.13 & 0.14 & 1.93 & 0.15 & 14.97 & 0.09 & 0.81 & 0.04 & 0.02 & 0.60 & 0.07 & 0.52 & 5.47 \\
\hline CZ- Czech Republic & 0.34 & 0.07 & 0.50 & 0.13 & 0.01 & 47.13 & 1.29 & 0.06 & 0.00 & 0.27 & 0.02 & 0.28 & 0.06 \\
\hline DE- Germany & 0.75 & 0.15 & 0.16 & 0.95 & 0.01 & 0.15 & 59.46 & 0.17 & 0.01 & 0.60 & 0.06 & 0.56 & 0.40 \\
\hline DK- Denmark & 0.13 & 0.16 & 0.03 & 0.34 & 0.01 & 0.09 & 1.28 & 56.12 & 0.03 & 0.56 & 0.35 & 0.58 & 0.09 \\
\hline EE- Estonia & 0.10 & 0.08 & 0.01 & 0.11 & 0.02 & 0.04 & 1.10 & 0.33 & 48.97 & 0.30 & 7.66 & 0.32 & 0.03 \\
\hline ES- Spain & 0.08 & 0.46 & 0.20 & 0.96 & 0.00 & 0.03 & 0.76 & 0.09 & 0.00 & 50.67 & 0.06 & 1.62 & 0.05 \\
\hline FI- Finland & 0.19 & 0.12 & 0.01 & 0.34 & 0.00 & 0.07 & 1.11 & 0.23 & 0.47 & 0.48 & 66.98 & 0.28 & 0.06 \\
\hline FR- France & 0.07 & 0.48 & 0.03 & 0.38 & 0.00 & 0.05 & 0.79 & 0.07 & 0.00 & 0.54 & 0.03 & 65.95 & 0.07 \\
\hline GR- Greece & 0.13 & 0.08 & 0.14 & 0.09 & 0.33 & 0.05 & 1.83 & 0.06 & 0.00 & 0.20 & 0.04 & 0.36 & 65.60 \\
\hline HU- Hungary & 1.19 & 0.14 & 0.05 & 0.21 & 0.02 & 0.12 & 4.18 & 0.10 & 0.00 & 0.30 & 0.08 & 0.69 & 0.08 \\
\hline IE- Ireland & 0.11 & 0.61 & 0.07 & 0.50 & 0.01 & 0.08 & 0.96 & 0.13 & 0.02 & 0.93 & 0.12 & 1.77 & 0.15 \\
\hline IS- Iceland & 0.21 & 0.09 & 0.01 & 0.21 & 0.00 & 0.08 & 1.43 & 9.32 & 0.03 & 0.96 & 0.59 & 0.42 & 0.04 \\
\hline IT- Italy & 0.12 & 0.17 & 0.02 & 0.95 & 0.00 & 0.04 & 0.88 & 0.05 & 0.00 & 0.46 & 0.03 & 0.46 & 0.04 \\
\hline LI- Liechtenstein & 2.77 & 0.04 & 0.02 & 2.29 & 0.00 & 0.03 & 3.14 & 0.34 & 0.00 & 0.75 & 0.01 & 2.48 & 0.03 \\
\hline LT- Lithuania & 0.17 & 0.20 & 0.08 & 0.17 & 0.01 & 0.10 & 2.32 & 0.74 & 0.05 & 1.56 & 0.11 & 0.46 & 0.08 \\
\hline LU- Luxembourg & 0.37 & 7.61 & 0.06 & 1.39 & 0.01 & 0.05 & 8.04 & 0.52 & 0.04 & 0.77 & 0.37 & 9.90 & 0.31 \\
\hline LV- Latvia & 0.09 & 0.15 & 0.07 & 0.24 & 0.03 & 0.04 & 1.33 & 0.45 & 0.25 & 0.33 & 0.18 & 0.34 & 0.05 \\
\hline MT- Malta & 0.11 & 0.22 & 0.02 & 0.14 & 0.02 & 0.04 & 0.71 & 0.08 & 0.00 & 0.19 & 0.03 & 1.97 & 0.06 \\
\hline NL- Netherlands & 0.19 & 2.06 & 0.05 & 0.40 & 0.01 & 0.12 & 1.90 & 0.14 & 0.00 & 0.79 & 0.07 & 0.83 & 0.15 \\
\hline NO- Norway & 0.08 & 0.08 & 0.02 & 0.19 & 0.00 & 0.06 & 0.80 & 1.40 & 0.04 & 0.95 & 0.56 & 0.29 & 0.05 \\
\hline PL- Poland & 0.40 & 0.32 & 0.03 & 0.29 & 0.02 & 0.26 & 6.68 & 0.29 & 0.00 & 0.56 & 0.06 & 0.68 & 0.18 \\
\hline PT- Portugal & 0.11 & 0.20 & 0.03 & 0.17 & 0.00 & 0.02 & 1.35 & 0.07 & 0.00 & 2.84 & 0.03 & 1.98 & 0.03 \\
\hline RO- Romania & 0.86 & 0.12 & 0.10 & 0.23 & 0.02 & 0.18 & 2.92 & 0.07 & 0.00 & 7.06 & 0.03 & 0.68 & 0.13 \\
\hline SE- Sweden & 0.15 & 0.14 & 0.02 & 0.35 & 0.01 & 0.07 & 0.94 & 1.14 & 0.05 & 0.58 & 1.45 & 0.44 & 0.22 \\
\hline SI- Slovenia & 1.04 & 0.29 & 0.01 & 1.28 & 0.00 & 0.08 & 1.43 & 0.07 & 0.00 & 0.21 & 0.02 & 0.25 & 0.02 \\
\hline SK- Slovakia & 1.46 & 0.13 & 0.14 & 1.29 & 0.05 & 11.00 & 2.92 & 0.11 & 0.00 & 0.40 & 0.03 & 0.46 & 0.09 \\
\hline UK- United Kingdom & 0.08 & 0.10 & 0.03 & 0.21 & 0.05 & 0.07 & 0.57 & 0.13 & 0.01 & 1.54 & 0.07 & 1.06 & 0.26 \\
\hline RW- Rest of World & 0.02 & 0.02 & 0.00 & 0.02 & 0.00 & 0.04 & 0.08 & 0.01 & 0.00 & 0.12 & 0.01 & 0.10 & 0.01 \\
\hline
\end{tabular}


DeWaard \& Raymer: The temporal dynamics of international migration in Europe

Table 3: (Continued)

\begin{tabular}{|c|c|c|c|c|c|c|c|c|c|c|c|c|}
\hline \multirow{2}{*}{\multicolumn{2}{|c|}{$\begin{array}{l}\text { Sending } \\
\text { Country } i\end{array}$}} & \multicolumn{11}{|c|}{ Receiving Country $j$} \\
\hline & & \multirow{2}{*}{$\begin{array}{l}\text { HU } \\
1.07\end{array}$} & \multirow{2}{*}{$\frac{\text { IE }}{0.08}$} & \multirow{2}{*}{$\frac{\text { IS }}{0.01}$} & \multirow{2}{*}{$\begin{array}{c}\text { IT } \\
0.62\end{array}$} & \multirow{2}{*}{$\frac{\text { LI }}{0.04}$} & \multirow{2}{*}{$\begin{array}{c}\text { LT } \\
0.01\end{array}$} & \multirow{2}{*}{$\frac{\text { LU }}{0.01}$} & \multirow{2}{*}{$\frac{\text { LV }}{0.01}$} & \multirow{2}{*}{$\begin{array}{l}\text { MT } \\
0.00\end{array}$} & \multirow{2}{*}{$\frac{\mathbf{N L}}{0.26}$} & \multirow{2}{*}{ NO } \\
\hline AT- & Austria & & & & & & & & & & & \\
\hline BE- & Belgium & 0.04 & 0.11 & 0.00 & 0.72 & 0.00 & 0.02 & 0.56 & 0.01 & 0.00 & 1.95 & 0.06 \\
\hline BG- & Bulgaria & 0.07 & 0.08 & 0.00 & 1.55 & 0.00 & 0.02 & 0.01 & 0.23 & 0.00 & 1.68 & 0.08 \\
\hline $\mathrm{CH}-$ & Switzerland & 0.10 & 0.19 & 0.01 & 4.94 & 0.01 & 0.03 & 0.04 & 0.02 & 0.01 & 0.60 & 0.15 \\
\hline CY- & Cyprus & 0.44 & 0.14 & 0.00 & 0.49 & 0.00 & 0.01 & 0.00 & 0.03 & 0.05 & 0.22 & 0.04 \\
\hline CZ- & Czech Republic & 0.04 & 0.04 & 0.01 & 0.31 & 0.00 & 0.01 & 0.00 & 0.03 & 0.00 & 0.17 & 0.05 \\
\hline DE- & Germany & 0.40 & 0.10 & 0.01 & 0.84 & 0.00 & 0.04 & 0.06 & 0.02 & 0.00 & 0.45 & 0.16 \\
\hline DK- & Denmark & 0.07 & 0.11 & 0.48 & 0.32 & 0.00 & 0.10 & 0.01 & 0.09 & 0.01 & 0.37 & 1.58 \\
\hline EE- & Estonia & 0.04 & 0.12 & 0.02 & 0.33 & 0.00 & 0.05 & 0.00 & 0.50 & 0.00 & 0.21 & 0.75 \\
\hline ES- & Spain & 0.04 & 0.26 & 0.00 & 0.37 & 0.01 & 0.04 & 0.01 & 0.01 & 0.00 & 0.26 & 0.05 \\
\hline $\mathrm{FI}-$ & Finland & 0.04 & 0.14 & 0.02 & 0.27 & 0.00 & 0.02 & 0.01 & 0.05 & 0.00 & 0.30 & 0.48 \\
\hline FR- & France & 0.04 & 0.11 & 0.00 & 0.38 & 0.00 & 0.01 & 0.16 & 0.01 & 0.01 & 0.21 & 0.04 \\
\hline GR- & Greece & 0.04 & 0.04 & 0.00 & 0.31 & 0.00 & 0.01 & 0.01 & 0.00 & 0.01 & 0.38 & 0.03 \\
\hline HU- & Hungary & 54.23 & 0.08 & 0.00 & 0.36 & 0.00 & 0.00 & 0.01 & 0.00 & 0.00 & 0.30 & 0.06 \\
\hline IE- & Ireland & 0.05 & 52.87 & 0.01 & 0.40 & 0.00 & 0.76 & 0.03 & 0.41 & 0.01 & 0.39 & 0.09 \\
\hline IS- & Iceland & 0.04 & 0.09 & 39.34 & 0.47 & 0.00 & 0.22 & 0.01 & 0.22 & 0.00 & 0.83 & 2.42 \\
\hline IT- & Italy & 0.02 & 0.04 & 0.00 & 71.03 & 0.00 & 0.01 & 0.01 & 0.01 & 0.01 & 0.14 & 0.02 \\
\hline LI- & Liechtenstein & 0.04 & 0.03 & 0.00 & 0.89 & 53.19 & 0.00 & 0.01 & 0.00 & 0.00 & 0.05 & 0.02 \\
\hline LT- & Lithuania & 0.02 & 2.26 & 0.17 & 0.52 & 0.00 & 47.81 & 0.01 & 0.56 & 0.00 & 0.33 & 1.70 \\
\hline LU- & Luxembourg & 0.30 & 0.20 & 0.04 & 1.40 & 0.00 & 0.06 & 29.73 & 0.01 & 0.02 & 0.96 & 0.08 \\
\hline LV- & Latvia & 0.01 & 0.84 & 0.08 & 0.34 & 0.00 & 0.27 & 0.00 & 50.30 & 0.00 & 0.18 & 0.47 \\
\hline MT- & Malta & 0.03 & 0.24 & 0.00 & 1.09 & 0.00 & 0.02 & 0.01 & 0.00 & 49.21 & 0.32 & 0.03 \\
\hline NL- & Netherlands & 0.09 & 0.13 & 0.01 & 0.34 & 0.00 & 0.02 & 0.03 & 0.02 & 0.01 & 58.92 & 0.18 \\
\hline NO- & Norway & 0.03 & 0.05 & 0.10 & 0.22 & 0.00 & 0.15 & 0.01 & 0.07 & 0.01 & 0.34 & 62.57 \\
\hline PL- & Poland & 0.05 & 1.01 & 0.13 & 0.96 & 0.00 & 0.03 & 0.02 & 0.02 & 0.00 & 0.71 & 0.81 \\
\hline PT- & Portugal & 0.02 & 0.05 & 0.03 & 0.24 & 0.00 & 0.02 & 0.48 & 0.01 & 0.00 & 0.61 & 0.05 \\
\hline RO- & Romania & 0.24 & 0.07 & 0.00 & 6.69 & 0.00 & 0.01 & 0.01 & 0.01 & 0.00 & 0.26 & 0.06 \\
\hline SE- & Sweden & 0.07 & 0.12 & 0.10 & 0.26 & 0.00 & 0.08 & 0.02 & 0.07 & 0.02 & 0.31 & 1.91 \\
\hline SI- & Slovenia & 0.03 & 0.03 & 0.00 & 0.79 & 0.02 & 0.00 & 0.02 & 0.00 & 0.00 & 0.21 & 0.05 \\
\hline SK- & Slovakia & 0.34 & 0.15 & 0.02 & 0.57 & 0.00 & 0.01 & 0.01 & 0.01 & 0.00 & 0.34 & 0.24 \\
\hline UK- & United Kingdom & 0.11 & 0.52 & 0.01 & 0.38 & 0.00 & 0.15 & 0.01 & 0.06 & 0.02 & 0.33 & 0.09 \\
\hline RW- & Rest of World & 0.01 & 0.01 & 0.00 & 0.14 & 0.00 & 0.00 & 0.00 & 0.00 & 0.00 & 0.02 & 0.01 \\
\hline
\end{tabular}


Demographic Research: Volume 26, Article 21

Table 3: (Continued)

\begin{tabular}{|c|c|c|c|c|c|c|c|c|c|c|c|}
\hline \multirow{2}{*}{$\begin{array}{l}\text { Sending } \\
\text { Country } i\end{array}$} & \multirow{3}{*}{$\begin{array}{c}\text { PL } \\
1.04\end{array}$} & \multirow{3}{*}{$\begin{array}{c}\text { PT } \\
0.10\end{array}$} & \multirow{3}{*}{$\frac{\text { RO }}{0.99}$} & \multirow{3}{*}{$\frac{\text { SE }}{0.15}$} & \multicolumn{4}{|c|}{ Receiving Country $j$} & \multirow{3}{*}{$\begin{array}{c}e_{0}^{i^{*}} \\
75.94\end{array}$} & \multirow{3}{*}{$\frac{e_{0}^{i i}}{51.51}$} & \multirow{2}{*}{$\sum_{j} e_{0}^{i j} \quad(i \neq j)$} \\
\hline & & & & & SI & SK & UK & RW & & & \\
\hline AT- Austria & & & & & 0.18 & 0.44 & 0.70 & 12.00 & & & \\
\hline BE- Belgium & 0.46 & 0.12 & 0.07 & 0.15 & 0.02 & 0.05 & 1.31 & 7.22 & 76.52 & 58.03 & 18.49 \\
\hline BG- Bulgaria & 0.40 & 0.08 & 0.57 & 0.43 & 0.01 & 0.26 & 1.10 & 10.36 & 73.48 & 43.85 & 29.63 \\
\hline $\mathrm{CH}-$ Switzerland & 0.69 & 0.20 & 0.15 & 0.40 & 0.36 & 0.22 & 2.68 & 8.52 & 77.10 & 45.41 & 31.69 \\
\hline CY- Cyprus & 0.26 & 0.03 & 1.43 & 0.19 & 0.00 & 0.04 & 3.58 & 40.65 & 72.55 & 14.97 & 57.58 \\
\hline CZ- Czech Republic & 0.22 & 0.02 & 0.19 & 0.07 & 0.01 & 1.39 & 1.21 & 20.02 & 73.97 & 47.13 & 26.84 \\
\hline DE- Germany & 2.86 & 0.18 & 0.41 & 0.21 & 0.06 & 0.13 & 1.01 & 6.25 & 76.59 & 59.46 & 17.13 \\
\hline DK- Denmark & 0.45 & 0.05 & 0.06 & 4.00 & 0.02 & 0.09 & 1.51 & 6.95 & 76.03 & 56.12 & 19.91 \\
\hline EE- Estonia & 0.13 & 0.02 & 0.03 & 1.12 & 0.00 & 0.02 & 2.55 & 8.03 & 73.02 & 48.97 & 24.05 \\
\hline Spain & 0.16 & 0.57 & 0.68 & 0.11 & 0.01 & 0.03 & 1.06 & 17.04 & 75.70 & 50.67 & 25.03 \\
\hline Finland & 0.13 & 0.02 & 0.02 & 1.95 & 0.01 & 0.03 & 0.60 & 2.40 & 76.83 & 66.98 & 9.85 \\
\hline FR- France & 0.28 & 0.26 & 0.08 & 0.08 & 0.01 & 0.04 & 1.18 & 5.71 & 77.06 & 65.95 & 11.11 \\
\hline GR- Greece & 0.45 & 0.02 & 0.18 & 0.24 & 0.00 & 0.03 & 1.36 & 4.90 & 76.95 & 65.60 & 11.34 \\
\hline HU- Hungary & 0.24 & 0.05 & 0.50 & 0.24 & 0.01 & 0.39 & 1.01 & 8.52 & 73.16 & 54.23 & 18.93 \\
\hline Ireland & 1.34 & 0.13 & 0.16 & 0.24 & 0.02 & 0.05 & 3.82 & 9.74 & 76.02 & 52.87 & 23.15 \\
\hline Iceland & 1.66 & 0.28 & 0.04 & 4.03 & 0.01 & 0.10 & 3.74 & 9.68 & 76.59 & 39.34 & 37.25 \\
\hline Italy & 0.31 & 0.03 & 0.08 & 0.06 & 0.02 & 0.05 & 0.46 & 2.67 & 78.18 & 71.03 & 7.15 \\
\hline Liechtenstein & 1.03 & 0.03 & 0.07 & 0.04 & 0.92 & 0.04 & 0.18 & 8.90 & 77.34 & 53.19 & 24.15 \\
\hline LT- Lithuania & 0.73 & 0.09 & 0.04 & 0.87 & 0.00 & 0.04 & 2.44 & 8.27 & 71.90 & 47.81 & 24.09 \\
\hline LU- Luxembourg & 0.67 & 3.76 & 0.12 & 0.50 & 0.21 & 0.04 & 3.55 & 5.75 & 76.86 & 29.73 & 47.13 \\
\hline LV- Latvia & 0.17 & 0.04 & 0.02 & 0.48 & 0.00 & 0.03 & 1.70 & 12.67 & 71.19 & 50.30 & 20.88 \\
\hline MT- Malta & 0.12 & 0.04 & 0.03 & 0.28 & 0.00 & 0.06 & 4.00 & 16.47 & 75.54 & 49.21 & 26.33 \\
\hline Netherlands & 0.58 & 0.17 & 0.07 & 0.27 & 0.01 & 0.06 & 1.60 & 7.67 & 76.90 & 58.92 & 17.98 \\
\hline NO- Norway & 0.58 & 0.05 & 0.03 & 3.18 & 0.00 & 0.11 & 1.45 & 4.00 & 77.47 & 62.57 & 14.90 \\
\hline Poland & 50.43 & 0.04 & 0.05 & 0.57 & 0.01 & 0.14 & 2.82 & 6.92 & 74.50 & 50.43 & 24.07 \\
\hline Portugal & 0.11 & 60.44 & 0.06 & 0.08 & 0.01 & 0.02 & 1.51 & 5.94 & 76.53 & 60.44 & 16.09 \\
\hline RO- Romania & 0.16 & 0.08 & 44.31 & 0.25 & 0.01 & 0.35 & 0.31 & 8.74 & 73.96 & 44.31 & 29.65 \\
\hline SE- Sweden & 0.69 & 0.04 & 0.04 & 61.82 & 0.03 & 0.06 & 1.41 & 4.99 & 77.60 & 61.82 & 15.78 \\
\hline Slovenia & 0.10 & 0.01 & 0.02 & 0.12 & 66.13 & 0.16 & 0.08 & 3.60 & 76.09 & 66.13 & 9.96 \\
\hline SK- Slovakia & 0.28 & 0.04 & 0.12 & 0.11 & 0.01 & 42.74 & 2.34 & 8.84 & 74.24 & 42.74 & 31.51 \\
\hline UK- United Kingdom & 0.38 & 0.10 & 0.05 & 0.20 & 0.01 & 0.05 & 61.65 & 8.12 & 76.41 & 61.65 & 14.76 \\
\hline RW- Rest of World & 0.03 & 0.01 & 0.01 & 0.02 & 0.00 & 0.01 & 0.15 & 58.37 & 59.24 & 58.37 & 0.87 \\
\hline
\end{tabular}

Source: Authors' calculations

Notes: The expected duration of residence of international migration is a conditional life expectancy at age zero, defined as the average number of years that a person is expected to live in the receiving country $j$ above age zero given prior residence in country $i$ at age zero (Willekens and Rogers 1978; see also Palloni 2001).

$e_{0}^{i^{*}} \quad=$ Total life expectancy above age zero in sending country $i$

$e_{0}^{i i} \quad=$ Average number of years a person can expect to live beyond age zero in country $i$ given prior residence in country $i$ at exact age zero

$\begin{aligned} \sum_{j} e_{0}^{i j}(i \neq j)= & \text { Average number of years a person can expect to live beyond age zero in any country but } i \text { given prior residence in } \\ & \text { country } i \text { at exact age zero }\end{aligned}$ 
DeWaard \& Raymer: The temporal dynamics of international migration in Europe

Table 4: Relative retention times (in years) for 31 EU/EFTA countries and rest of world, 2002-2007

\begin{tabular}{|c|c|c|c|c|c|c|c|c|c|c|}
\hline & & & & & & & & $e_{0}^{i^{\star}}$ & $\begin{array}{c}\% \text { change in } \\
e_{0}^{i^{*}}\end{array}$ & $\begin{array}{c}e_{0}^{\prime \prime} \text { as \% of } \\
e_{0}^{i^{*}}\end{array}$ \\
\hline Coun & & 2002 & 2003 & 2004 & 2005 & 2006 & 2007 & 2007 & 2002-2007 & 2007 \\
\hline RW- & Rest of World & 56.54 & 56.85 & 57.20 & 57.66 & 58.01 & 58.37 & 59.24 & 3.47 & 98.53 \\
\hline IT- & Italy & 70.89 & 70.32 & 71.09 & 71.02 & 71.35 & 71.03 & 78.18 & 0.96 & 90.85 \\
\hline FI- & Finland & 66.49 & 67.08 & 66.33 & 66.99 & 67.31 & 66.98 & 76.83 & 0.76 & 87.17 \\
\hline SI- & Slovenia & 66.87 & 67.09 & 66.89 & 67.98 & 67.66 & 66.13 & 76.09 & 1.48 & 86.91 \\
\hline FR- & France & 68.47 & 68.20 & 67.87 & 67.30 & 66.32 & 65.95 & 77.06 & 0.93 & 85.58 \\
\hline GR- & Greece & 65.80 & 66.51 & 66.24 & 66.20 & 66.32 & 65.60 & 76.95 & 0.61 & 85.26 \\
\hline NO- & Norway & 60.79 & 61.10 & 61.98 & 62.83 & 62.43 & 62.57 & 77.47 & 1.28 & 80.76 \\
\hline UK- & United Kingdom & 62.18 & 61.98 & 62.04 & 61.69 & 60.26 & 61.65 & 76.41 & 1.13 & 80.68 \\
\hline SE- & Sweden & 65.02 & 64.26 & 63.72 & 63.24 & 62.03 & 61.82 & 77.60 & 0.56 & 79.67 \\
\hline PT- & Portugal & 63.29 & 62.97 & 62.94 & 62.56 & 61.47 & 60.44 & 76.53 & 1.66 & 78.97 \\
\hline DE- & Germany & 61.93 & 61.79 & 60.18 & 61.15 & 61.01 & 59.46 & 76.59 & 1.11 & 77.64 \\
\hline NL- & Netherlands & 63.02 & 62.50 & 61.58 & 60.40 & 59.27 & 58.92 & 76.90 & 1.12 & 76.61 \\
\hline BE- & Belgium & 61.69 & 61.38 & 60.84 & 60.14 & 58.79 & 58.03 & 76.52 & 0.94 & 75.84 \\
\hline $\mathrm{HU}-$ & Hungary & 57.98 & 58.48 & 57.27 & 56.05 & 55.26 & 54.23 & 73.16 & 1.53 & 74.12 \\
\hline DK- & Denmark & 57.89 & 57.49 & 56.62 & 56.36 & 55.46 & 56.12 & 76.03 & 1.17 & 73.82 \\
\hline LV- & Latvia & 52.13 & 56.36 & 55.19 & 55.28 & 47.04 & 50.30 & 71.19 & 1.56 & 70.67 \\
\hline IE- & Ireland & 58.53 & 58.39 & 56.80 & 56.20 & 54.29 & 52.87 & 76.02 & 0.89 & 69.55 \\
\hline LI- & Liechtenstein & 57.51 & 60.39 & 54.17 & 54.89 & 55.64 & 53.19 & 77.34 & 1.37 & 68.77 \\
\hline AT- & Austria & 60.32 & 57.41 & 55.78 & 55.13 & 52.19 & 51.51 & 75.94 & 0.16 & 67.82 \\
\hline PL- & Poland & 57.84 & 57.58 & 55.62 & 53.97 & 48.70 & 50.43 & 74.50 & 1.21 & 67.69 \\
\hline EE- & Estonia & 52.68 & 53.35 & 51.57 & 51.54 & 49.88 & 48.97 & 73.02 & 2.59 & 67.06 \\
\hline ES- & Spain & 70.29 & 66.92 & 67.52 & 66.13 & 58.23 & 50.67 & 75.70 & -1.44 & 66.94 \\
\hline LT- & Lithuania & 56.30 & 52.77 & 49.67 & 48.29 & 49.05 & 47.81 & 71.90 & 0.79 & 66.49 \\
\hline MT- & Malta & 53.58 & 53.64 & 52.08 & 51.81 & 48.89 & 49.21 & 75.54 & 0.29 & 65.15 \\
\hline CZ- & Czech Republic & 41.66 & 39.87 & 39.68 & 44.24 & 38.39 & 47.13 & 73.97 & 1.87 & 63.72 \\
\hline RO- & Romania & 50.41 & 42.46 & 44.93 & 47.77 & 46.14 & 44.31 & 73.96 & 3.37 & 59.91 \\
\hline BG- & Bulgaria & 53.47 & 51.23 & 50.98 & 51.04 & 49.29 & 43.85 & 73.48 & 1.89 & 59.67 \\
\hline $\mathrm{CH}-$ & Switzerland & 48.43 & 49.13 & 48.75 & 48.29 & 45.78 & 45.41 & 77.10 & 0.66 & 58.90 \\
\hline SK- & Slovakia & 49.39 & 51.03 & 49.97 & 43.86 & 42.72 & 42.74 & 74.24 & 1.29 & 57.56 \\
\hline IS- & Iceland & 43.40 & 44.59 & 42.68 & 43.03 & 41.45 & 39.34 & 76.59 & -0.01 & 51.37 \\
\hline LU- & Luxembourg & 31.38 & 29.80 & 30.12 & 29.54 & 32.27 & 29.73 & 76.86 & 1.54 & 38.68 \\
\hline CY- & Cyprus & 20.13 & 28.60 & 22.13 & 16.44 & 21.60 & 14.97 & 72.55 & 0.87 & 20.64 \\
\hline
\end{tabular}

Source: Authors' calculations 
The information in Table 4 is also useful for examining the effects of EU expansions in 2004 and 2007. Overall, we find that most countries in the EU/EFTA exhibited lower levels of retention in 2007 compared to 2002, suggesting an increase in mobility during this time. Interestingly, these decreases are neither consistent nor apparent across all countries in the system. For example, consider Poland, the largest new EU accession country, which joined in 2004. In 2007 persons at age zero living in Poland could expect to live, on average, 50.4 years of their 74.5 years above age zero in Poland. Between 2002 and 2007 life expectancy in Poland increased by 1.2\%; however, the average years lived in Poland above age zero decreased by over seven years over the period. For Bulgaria the corresponding decrease was 9.6 years, most of which occurred in 2007 when Bulgaria joined the EU. Not all decreases, however, represent recent accessions to the EU. People living in Austria at age zero, for example, exhibited a considerable decrease in the average years lived in Austria. In 2002 persons living in Austria at age zero could expect to live 60.3 years above age zero in that country. In 2007 this figure was 51.5 years, a decrease of 8.8 years. In Spain the corresponding drop was nearly 20 years. Increasing foreign populations and return migration could be responsible for some, if not most, of these decreases. The figures for Finland and Norway, on the other hand, increased by one-half of one year and almost two years, respectively. Other countries, such as Greece, Germany, Italy, and the UK remained at about the same levels over the six-year period.

Our final set of illustrations in this section focus on particular flows between pairs of sending and receiving countries. In Figure 2 we present the expected duration of residence in each EU-15 country (defined as EU members prior to 2004) by persons residing in Poland at age zero each year from 2002 to 2007. The average number of years lived by persons from Poland in Germany and the UK increased considerably after 2003. For the UK this is expected, as Polish migrants were welcomed at the time of accession. For Germany, however, this is somewhat surprising as Germany restricted flows from new accession countries. Our results suggest that, while flows may have been restricted (see Table 2), the policy may have actually encouraged those already in Germany to stay longer than they would have otherwise. 
Figure 2: Expected duration of residence (in years) for persons from Poland to EU-15 countries, 2002-2007

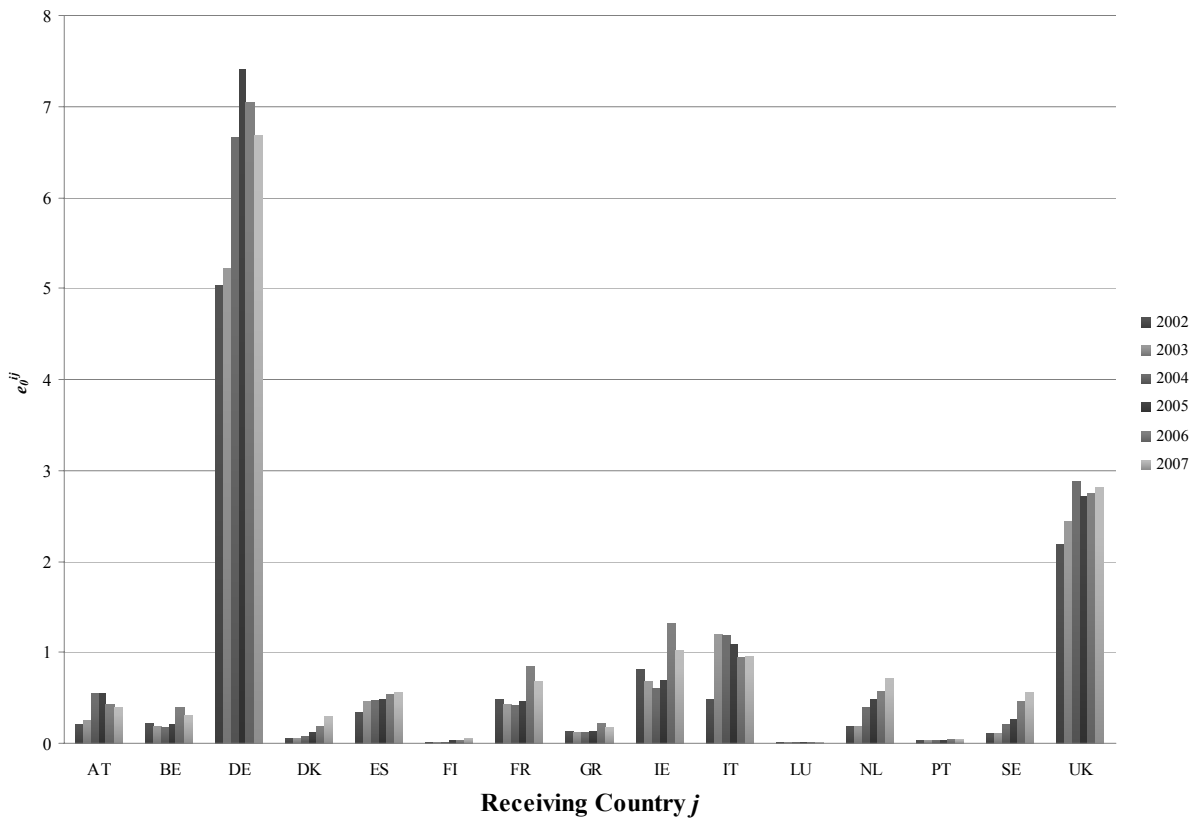

In Figure 3 selected flows from other recent EU accession countries to the EU-15 are presented to illustrate different patterns resulting from our estimates. Here we see that those originating in Bulgaria were more likely to migrate to and reside in Germany and Spain relative to other EU-15 countries. Until 2006 the average number of years lived in Germany had been decreasing. In 2007, however, the number of years lived in Germany more than doubled, from 2.0 years to 4.8 years. Patterns for the Czech Republic and Slovenia were relatively stable over time with no large effects following their accessions to the EU. The number of years that persons originating in Estonia could expect to live in Finland more than doubled between 2002 and 2007, but the patterns for other EU-15 countries, e.g., the UK, remained about the same.

Finally, in Figure 4, we present flows between the four Nordic countries, i.e., Denmark, Finland, Norway, and Sweden, to see how these patterns have changed over time. Persons living in Denmark at age zero could expect to live about the same amount of time in Norway over the 2002-2007 period, whereas the number of years lived in Sweden increased by roughly one year and one-half. For persons living in Finland and 
Norway at age zero, the number of years expected to live in Sweden decreased, whereas for persons living in Sweden at age zero, the number of years lived in Finland and Norway trended in the opposite direction.

Figure 3: Expected duration of residence (in years) for persons from selected new accession countries to $\mathrm{EU}-15$ countries, 2002-2007

Panel A: $\quad$ Sending country $i=$ Bulgaria

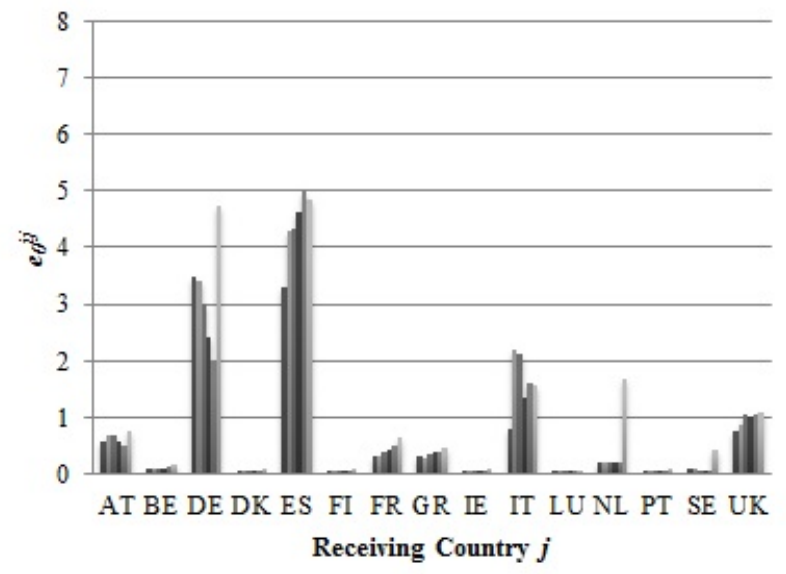

Panel B: $\quad$ Sending country $i=$ Czech Republic

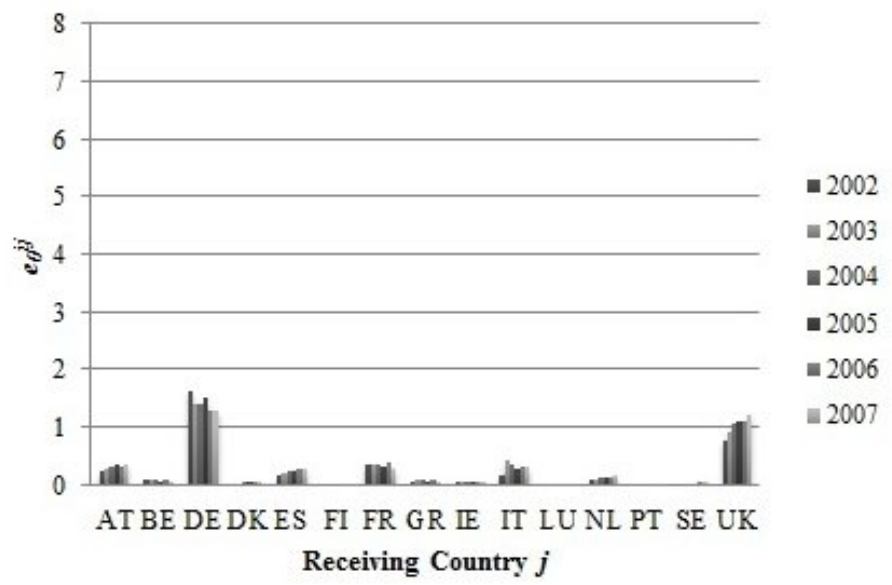


Figure 3: (Continued)

Panel C: $\quad$ Sending country $i=$ Slovenia

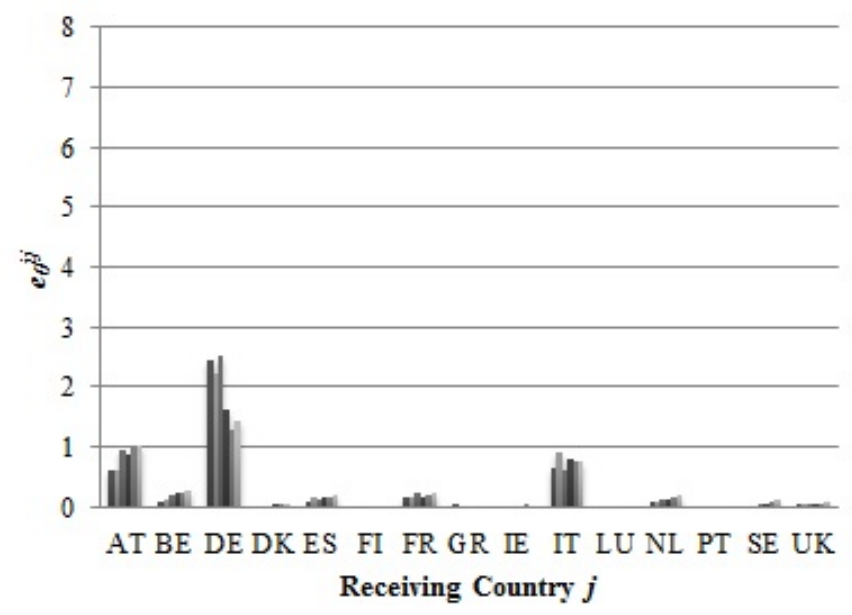

\section{Panel D: $\quad$ Sending country $i=$ Estonia}

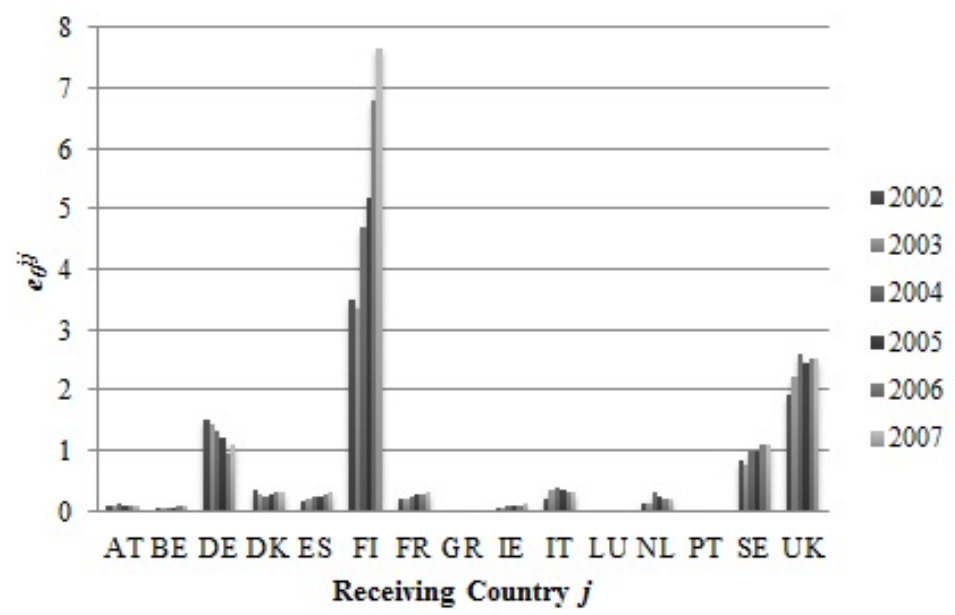


Figure 4: Expected duration of residence (in years) for persons among Nordic countries, 2002-2007

Panel A: $\quad$ Sending country $i=$ Denmark

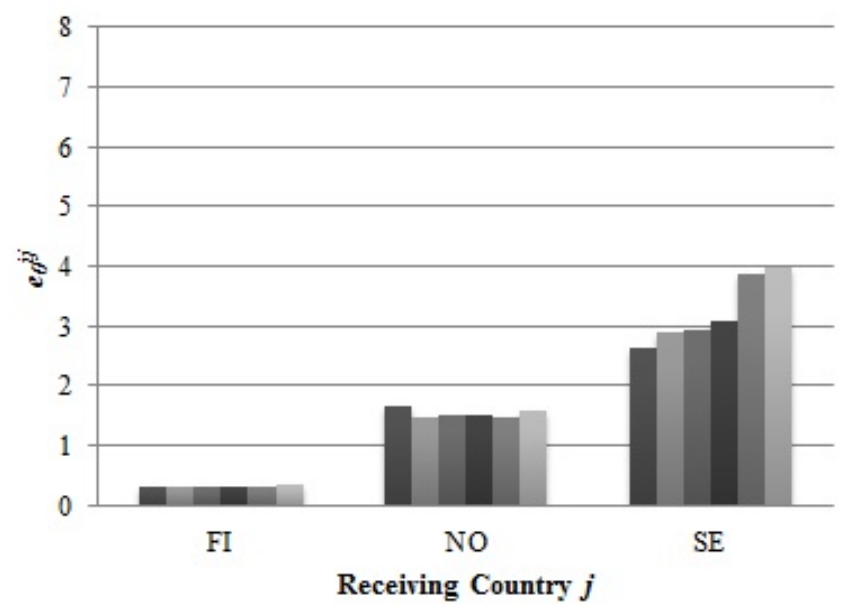

Panel B: $\quad$ Sending country $i=$ Finland

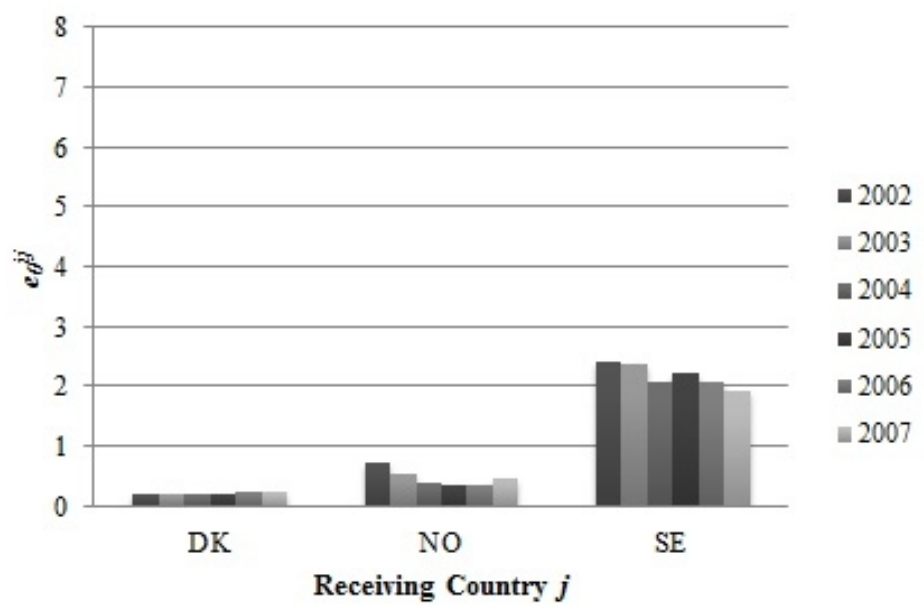


Figure 4: (Continued)

Panel C: $\quad$ Sending country $i=$ Norway

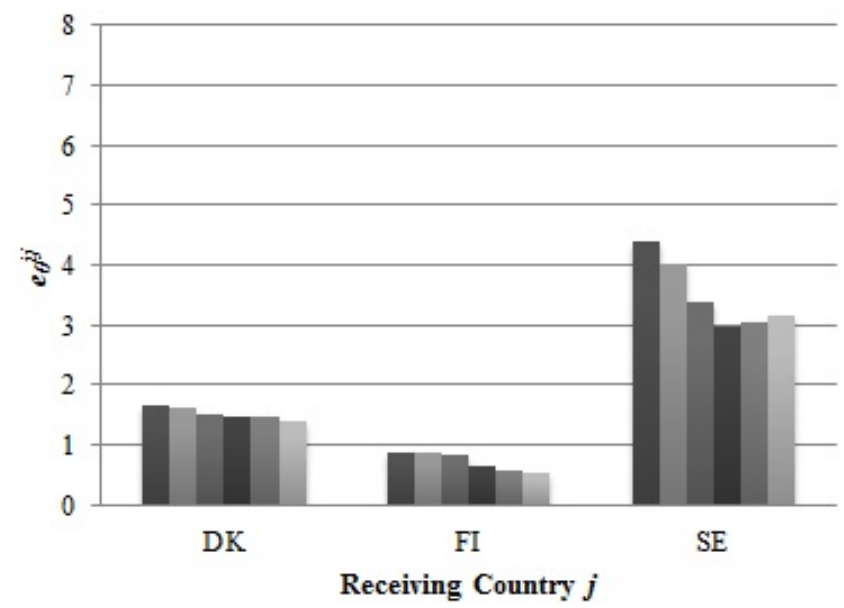

Panel D: $\quad$ Sending country $i=$ Sweden

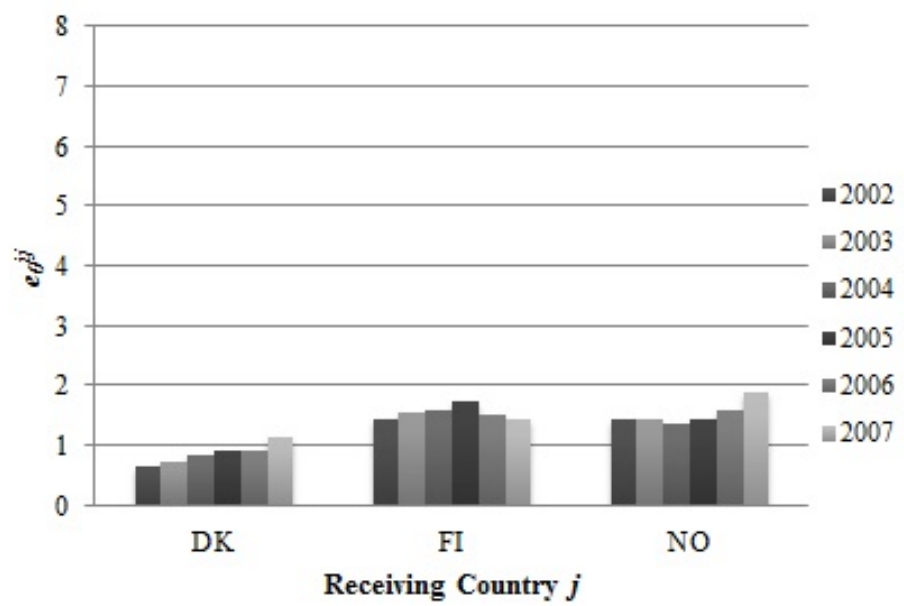




\subsubsection{Summarizing the expected duration of residence for receiving countries}

While well-known in the multistate literature (Palloni 2001; Rogers 1975, 1995; Schoen 1988), the expected durations of residence as discussed in Section 4.2 provide only a partial picture of the temporal dynamics of international migration, because they can only be interpreted with respect to the single sending country $i$. However, as we demonstrated earlier in Equations (6)-(9), one need not condition on a single sending country. Thus, toward extending the measure described in Equation (5), we present in Table 5 the expected durations of residence for each receiving country in the EU/EFTA and the Rest of the World, wherein, for each destination, we condition on any and all sending countries (for $i \neq j$ ). These quantities thus express the average number of years that a person is expected to live in receiving country $j$ beyond age zero given previous residence outside of $j$, i.e., in any and all sending countries $(i=1,2, \ldots, k$ for $i \neq j)$, at age zero. Weighted averages are presented for each receiving country. As noted earlier, the weights are proportional to the size of the migration flow from each sending country.

Table 5: $\quad$ Expected duration of residence (in years) weighted by size of migration flow and summed by destination: 31 EU/EFTA receiving countries and rest of world, 2002-2007

\begin{tabular}{|c|c|c|c|c|c|c|c|}
\hline \multicolumn{2}{|c|}{ Receiving Country } & \multirow{2}{*}{$\frac{2002}{0.43}$} & \multirow{2}{*}{$\begin{array}{r}2003 \\
0.48\end{array}$} & \multirow{2}{*}{$\begin{array}{r}2004 \\
0.61\end{array}$} & \multirow{2}{*}{$\begin{array}{r}2005 \\
0.63\end{array}$} & \multirow{2}{*}{$\begin{array}{r}2006 \\
0.61\end{array}$} & \multirow{2}{*}{$\begin{array}{r}\mathbf{2 0 0 7} \\
0.72\end{array}$} \\
\hline AT- & Austria & & & & & & \\
\hline BE- & Belgium & 1.09 & 1.14 & 1.18 & 1.09 & 1.11 & 1.07 \\
\hline BG- & Bulgaria & 0.48 & 0.39 & 0.43 & 0.45 & 0.40 & 0.38 \\
\hline $\mathrm{CH}-$ & Switzerland & 0.65 & 0.68 & 0.62 & 0.63 & 0.64 & 0.81 \\
\hline CY- & Cyprus & 0.13 & 0.21 & 0.23 & 0.20 & 0.16 & 0.14 \\
\hline CZ- & Czech Republic & 3.53 & 4.29 & 3.60 & 4.31 & 4.23 & 7.55 \\
\hline DE- & Germany & 3.01 & 2.99 & 3.79 & 4.28 & 4.15 & 4.05 \\
\hline DK- & Denmark & 0.98 & 0.92 & 1.00 & 0.88 & 0.85 & 0.85 \\
\hline EE- & Estonia & 0.21 & 0.08 & 0.23 & 0.15 & 0.20 & 0.21 \\
\hline ES- & Spain & 2.76 & 3.56 & 3.41 & 3.53 & 3.76 & 3.82 \\
\hline $\mathrm{Fl}-$ & Finland & 1.06 & 1.06 & 1.38 & 1.54 & 1.97 & 2.16 \\
\hline FR- & France & 1.15 & 1.14 & 1.26 & 1.39 & 1.40 & 1.61 \\
\hline GR- & Greece & 0.81 & 0.55 & 0.70 & 0.98 & 0.68 & 1.03 \\
\hline HU- & Hungary & 0.30 & 0.30 & 0.62 & 0.33 & 0.37 & 0.40 \\
\hline IE- & Ireland & 0.54 & 0.48 & 0.49 & 0.76 & 0.89 & 0.73 \\
\hline IS- & Iceland & 0.17 & 0.13 & 0.16 & 0.19 & 0.21 & 0.18 \\
\hline IT- & Italy & 2.53 & 6.93 & 5.60 & 3.59 & 4.12 & 3.99 \\
\hline 나- & Liechtenstein & 0.00 & $<0.01$ & $<0.01$ & $<0.01$ & 0.01 & 0.02 \\
\hline LT- & Lithuania & 0.08 & 0.06 & 0.06 & 0.11 & 0.20 & 0.23 \\
\hline LU- & Luxembourg & 0.35 & 0.35 & 0.35 & 0.33 & 0.27 & 0.28 \\
\hline LV- & Latvia & 0.12 & 0.13 & 0.17 & 0.23 & 0.16 & 0.19 \\
\hline
\end{tabular}


DeWaard \& Raymer: The temporal dynamics of international migration in Europe

Table 5: (Continued)

\begin{tabular}{llcccccc}
\hline Receiving Country & $\mathbf{2 0 0 2}$ & $\mathbf{2 0 0 3}$ & $\mathbf{2 0 0 4}$ & $\mathbf{2 0 0 5}$ & $\mathbf{2 0 0 6}$ & $\mathbf{2 0 0 7}$ \\
\hline MT- & Malta & 0.01 & 0.01 & 0.01 & 0.02 & 0.02 & 0.01 \\
NL- & Netherlands & 0.49 & 0.48 & 0.47 & 0.49 & 0.54 & 0.69 \\
NO- & Norway & 0.92 & 0.81 & 0.69 & 0.67 & 0.70 & 0.89 \\
PL- & Poland & 1.09 & 1.16 & 1.53 & 1.51 & 1.51 & 2.12 \\
PT- & Portugal & 0.38 & 0.39 & 0.44 & 0.40 & 0.37 & 0.47 \\
RO- & Romania & 0.33 & 0.33 & 0.39 & 0.43 & 0.46 & 0.55 \\
SE- & Sweden & 1.78 & 1.70 & 1.41 & 1.33 & 1.39 & 1.31 \\
SI- & Slovenia & 0.08 & 0.06 & 0.06 & 0.09 & 0.09 & 0.15 \\
SK- & Slovakia & 0.16 & 0.19 & 0.25 & 0.60 & 0.72 & 0.56 \\
UK- & United Kingdom & 1.39 & 1.59 & 1.88 & 1.76 & 1.81 & 1.82 \\
RW- & Rest of World & 9.55 & 9.50 & 9.85 & 9.13 & 11.02 & 11.25 \\
\hline
\end{tabular}

Notes: The expected duration of residence in the receiving country is interpreted as the average number of years that a person is expected to live in receiving country $j$ above age zero given prior residence outside of country $j$ at age zero (Willekens and Rogers 1978; see also Palloni 2001).

The quantities in Table 5 can be interpreted as follows: using Germany in 2007 as an example, 4.05 is the average number of years that a person is expected to live in Germany above age zero given previous residence in any other EU/EFTA country or the rest of the world at age zero. Recall that the interpretation of this measure assumes constant age-specific migration and mortality schedules prevailing during the period in question, e.g., in 2007. This measure reflects migration at the population level, i.e., the set of all persons exposed to the risk of migration, rather than simply those who happened to migrate during a given period. This explains why some of the estimates, e.g., Lichtenstein, are effectively zero. As weighted averages, these estimates account for the fact that the size of migration flows to a receiving country can and often does differ substantially by the sending country. For example, in 2007 , nearly $40 \%$ of flows to Germany originated from countries outside of the EU/EFTA (not shown). The corresponding figure for the UK was $67 \%$.

In contrast to Table 2, where rates of net-migration are overwhelmingly positive for countries in Northern, Western, and Southern Europe, the variation in the expected duration of residence is considerable. Luxembourg, Switzerland, and Austria exhibit the highest rates of net-migration each year, whereas the Czech Republic, Germany, Italy, and Spain have the highest expected durations of residence of international migration in Table 5. Moreover, excluding the Czech Republic, it is noteworthy that the latter set of countries corresponds to those detailed by Castles and Miller (2003) in their account of both historically and emerging key destination countries in Europe over the past half century. Simply stated, the quantities in Table 5 closely align with intuitive notions of contemporary migration patterns in Europe. 
Discrepancies between the volume and temporal dynamics of migration are also evident among relatively homogenous pairs of countries. While, in Table 2, both Norway and Sweden showed similarly positive rates of net-migration in 2007, of 6.06 and 6.01 per thousand, respectively, the expected duration of residence in Sweden (1.31 years) is nearly double that of Norway ( 0.89 years). Likewise, Ireland and the UK, with rates of net-migration in 2007 of 5.71 and 4.41 per thousand, respectively, exhibit differences in the expected durations of residence. The figure for the UK (1.82 years) is more than double that for Ireland ( 0.73 years). Although there exist extensive literatures on the unique historical, geopolitical, economic, and sociocultural sources of these differences (Castles and Miller 2003; DeWaard, Kim and Raymer forthcoming; Jennissen 2004; Kritz, Lim and Zlotnik 1992; Massey et al. 1998), our aim is more modest and is simply to document discrepancies between the volume and the expected duration of residence of international migration. At present we have fairly strong evidence that these dynamics should be examined concurrently in descriptive accounts of international migration.

\subsubsection{Heterogeneity by citizenship and age}

Like many demographic processes, flows of migrants between sending and receiving countries are composed of heterogeneous subpopulations (Vaupel and Yashin 1985). With respect to our estimates, one of the most obvious sources of heterogeneity is migrants leaving and returning to their country of birth. Multistate life tables with this type of origin-dependence were developed and explored for internal migration in the United States by Rogers and Philipov (1979), Ledent (1981) and Philipov and Rogers (1981), and were also detailed by Rogers (1995:140-176). These developments followed earlier analyses, which demonstrated key differences between primary, secondary (or repeat), and return migration using cross-classified U.S. Census data on place-of-residence by place-of-residence-five-years-ago by place-of-birth (Eldridge 1965; Long and Hansen 1977). Primary migrants are those who migrated away from their place of birth. Return migrants are those who migrated to their place of birth. And secondary migrants are those who migrated neither away from nor to their place of birth. For empirical analyses examining these types of migration over time, refer to Rogers and Belanger (1990) and Rogers and Raymer (2005).

The above works yielded several important considerations when examining directional migration flows within the United States. First, the propensity to migrate, controlling for the populations at risk, is much higher for return migration than for primary migration. Second, the age patterns of migration differ according to the type of move, with return migrants exhibiting a slightly older labor force peak. Third, return 
migration occurs in both directions. Fourth, the patterns of primary, secondary, and return migration tend to be stable over time. Finally, the retention expectancies, i.e., those who remained in their place of residence, are higher when origin-dependence is included. For example, Rogers and Belanger (1990:204) showed that retention expectancies, expressed in percentages, for birthplace-independent life tables from 1980 U.S. Census data were 53\% for New England, 58\% for the South Atlantic, $61 \%$ for the West South Central, and $41 \%$ for the Mountain region. The corresponding retention expectancies from birthplace-dependent life tables were $74 \%, 83 \%, 85 \%$, and $72 \%$, respectively.

Unfortunately, consistent and complete birthplace-specific international migration flow tables are unavailable. We therefore have no way to directly test the sensitivity of our results in the presence of return migration to the country of birth. However, toward indirectly exploring this heterogeneity, and thus the Markov assumption, we incorporated age-specific migration data classified by type of citizenship from the MIMOSA project. ${ }^{18}$ We combined the 2007 estimates of total age-specific emigration for nationals and foreigners with the corresponding population stocks to obtain agespecific emigration rates for both nationals and foreigners. ${ }^{19}$ Although not ideal, these estimates allowed us to test, albeit indirectly, the effects of migrant heterogeneity. We assume that most foreign emigrants are return migrants and most national emigrants are primary migrants. We focus our discussion on the retention expectances (like those in Table 4) for nationals and foreigners, expressed as the percentage of remaining years of life to be lived in country $i$ above ages zero, 20, and 40 given previous residence in $i$ at exact ages zero, 20 , and 40 , respectively.

\footnotetext{
${ }^{18}$ Available at http://www.knaw.nl/Pages/NID/24/928.bGFuZz1VSw.html.

${ }^{19}$ Bulgaria, Cyprus, Czech Republic, Hungary, Lithuania, Malta, Romania, Slovenia and Slovakia all reported very small foreign populations, and, in some cases, the estimated foreign migration flows were nearly the same size or even larger than the foreign population stocks. For these countries we assumed the foreign emigration rates were the same as Poland's, which appeared more reasonable.
} 
Table 6: Relative retention times (as percentage of remaining life) for 31 EU/EFTA countries and rest of world by citizenship and age, 2007

\begin{tabular}{|c|c|c|c|c|c|c|c|c|c|c|}
\hline \multirow{2}{*}{\multicolumn{2}{|c|}{ Country }} & \multicolumn{3}{|c|}{ All Persons } & \multicolumn{3}{|c|}{ Nationals } & \multicolumn{3}{|c|}{ Foreigners } \\
\hline & & $\mathbf{e}_{0}^{i i} / \mathbf{e}_{0}^{i^{i *}}$ & $\mathrm{e}_{20}{ }^{i i} / \mathrm{e}_{20^{j^{*}}}$ & $\mathbf{e}_{40^{i i}} / \mathbf{e}_{40^{i *}}$ & $\mathbf{e}_{0}^{i i /} / \mathbf{e}_{0}^{i^{*}}$ & $\mathrm{e}_{20}{ }^{i i} / \mathrm{e}_{20}{ }^{i^{*}}$ & $\mathbf{e}_{40}{ }^{i i} / \mathbf{e}_{40^{i *}}$ & $\mathbf{e}_{0}^{i i} / \mathbf{e}_{0}{ }^{i^{*}}$ & $\mathrm{e}_{20}{ }^{i i} / \mathrm{e}_{20^{i^{*}}}$ & $\mathbf{e}_{40}{ }^{i i} / \mathbf{e}_{40}{ }^{i t}$ \\
\hline AT- & Austria & 67.82 & 66.52 & 87.90 & 86.93 & 88.85 & 96.25 & 24.10 & 13.86 & 35.60 \\
\hline BE- & Belgium & 75.84 & 75.56 & 93.58 & 88.49 & 90.09 & 97.43 & 27.03 & 18.31 & 62.92 \\
\hline BG- & Bulgaria & 59.67 & 60.10 & 85.93 & 80.13 & 84.28 & 94.75 & 26.04 & 14.72 & 78.15 \\
\hline $\mathrm{CH}-$ & Switzerland & 58.90 & 58.74 & 87.08 & 75.73 & 80.38 & 94.53 & 31.41 & 21.41 & 63.07 \\
\hline CY- & $\begin{array}{l}\text { Cyprus } \\
\text { Czech }\end{array}$ & 20.64 & 11.93 & 51.26 & 83.04 & 85.97 & 95.29 & 28.63 & 19.92 & 80.81 \\
\hline CZ- & Republic & 63.72 & 58.60 & 81.42 & 97.39 & 97.62 & 99.03 & 29.51 & 21.02 & 80.09 \\
\hline DE- & Germany & 77.64 & 76.80 & 91.71 & 92.52 & 93.69 & 97.88 & 27.61 & 22.71 & 43.54 \\
\hline DK- & Denmark & 73.82 & 74.88 & 96.16 & 82.18 & 84.78 & 97.70 & 26.16 & 18.29 & 66.76 \\
\hline EE- & Estonia & 67.06 & 68.30 & 90.27 & 81.73 & 84.77 & 95.13 & 31.69 & 24.75 & 73.85 \\
\hline ES- & Spain & 66.94 & 67.14 & 88.22 & 91.93 & 93.73 & 97.91 & 19.22 & 14.78 & 31.20 \\
\hline Fl- & Finland & 87.17 & 88.74 & 97.52 & 89.03 & 90.96 & 97.97 & 45.81 & 42.87 & 73.24 \\
\hline FR- & France & 85.58 & 85.27 & 96.11 & 93.56 & 94.30 & 98.38 & 43.14 & 38.19 & 80.15 \\
\hline GR- & Greece & 85.26 & 86.00 & 96.11 & 92.83 & 94.35 & 98.46 & 49.44 & 43.79 & 65.91 \\
\hline HU- & Hungary & 74.12 & 69.96 & 88.33 & 96.73 & 96.90 & 98.85 & 26.71 & 15.94 & 78.43 \\
\hline IE- & Ireland & 69.55 & 68.94 & 88.57 & 84.29 & 85.62 & 95.12 & 25.74 & 25.04 & 38.47 \\
\hline IS- & Iceland & 51.37 & 54.89 & 93.45 & 55.73 & 61.11 & 93.96 & 12.43 & 11.39 & 70.13 \\
\hline IT- & Italy & 90.85 & 92.28 & 96.89 & 91.98 & 93.65 & 97.02 & 76.51 & 74.41 & 78.22 \\
\hline 니- & Liechtenstein & 68.77 & 66.31 & 92.39 & 74.62 & 77.26 & 92.94 & 42.62 & 36.04 & 80.54 \\
\hline LT- & Lithuania & 66.49 & 68.37 & 90.65 & 70.40 & 73.42 & 92.08 & 25.85 & 14.17 & 77.84 \\
\hline LU- & Luxembourg & 38.68 & 36.66 & 68.86 & 66.63 & 76.59 & 91.71 & 26.66 & 18.55 & 44.75 \\
\hline LV- & Latvia & 70.67 & 72.61 & 86.09 & 74.85 & 78.51 & 88.76 & 55.73 & 51.98 & 75.25 \\
\hline MT- & Malta & 65.15 & 63.76 & 89.91 & 83.00 & 85.39 & 95.86 & 27.44 & 17.76 & 80.30 \\
\hline NL- & Netherlands & 76.61 & 79.04 & 92.83 & 80.95 & 84.15 & 94.72 & 33.67 & 32.72 & 52.17 \\
\hline NO- & Norway & 80.76 & 82.22 & 95.59 & 89.76 & 92.14 & 98.04 & 24.79 & 18.68 & 53.05 \\
\hline PL- & Poland & 67.69 & 66.01 & 88.17 & 67.37 & 65.72 & 88.10 & 28.67 & 18.84 & 79.75 \\
\hline PT- & Portugal & 78.97 & 79.95 & 94.27 & 90.36 & 92.42 & 97.84 & 19.77 & 8.58 & 32.54 \\
\hline RO- & Romania & 59.91 & 53.12 & 79.09 & 80.55 & 79.50 & 91.70 & 26.67 & 15.84 & 78.19 \\
\hline SE- & Sweden & 79.67 & 81.69 & 94.56 & 86.25 & 89.13 & 96.81 & 32.70 & 31.31 & 61.82 \\
\hline SI- & Slovenia & 86.91 & 88.84 & 94.79 & 93.75 & 95.74 & 97.92 & 26.04 & 15.07 & 79.14 \\
\hline & $\begin{array}{l}\text { Slovakia } \\
\text { United }\end{array}$ & 57.56 & 53.07 & 77.92 & 72.93 & 72.93 & 88.06 & 27.38 & 17.13 & 78.64 \\
\hline UK- & Kingdom & 80.68 & 80.75 & 94.23 & 87.56 & 88.44 & 96.42 & 38.36 & 36.67 & 54.58 \\
\hline
\end{tabular}

Source: Authors' calculations 
As expected, our results show that nationals have considerably higher retention expectancies and foreigners have considerably lower retention expectancies than do all migrants combined. For example, persons living in Austria at age zero can expect to spend $67.8 \%$ of their lives in Austria. When citizenship is considered, the figure increases to $86.9 \%$ for nationals and decreases to $24.1 \%$ for foreigners. This pattern is consistent across all countries. Some of the differences between nationals and foreigners, e.g., Spain and Portugal, are particularly large with over $90 \%$ retention for nationals and less than $20 \%$ for foreigners. For other countries the differences between nationals and foreigners are smaller. For example, Latvia exhibited retention expectancies of $74.9 \%$ for nationals and $55.7 \%$ for foreigners.

We also found considerable heterogeneity across age. For nationals, the retention expectancies increased as age increased. For example, Luxembourg exhibited retention expectancies of $66.6 \%, 76.6 \%$, and $91.7 \%$ at ages zero, 20 , and 40 , respectively (see also Iceland). In other cases the differences between ages zero and 20 were not so large. For example, Poland exhibited a retention expectancy of $67.4 \%$ at age zero, which decreased slightly to $65.7 \%$ at age 20 , and then increased dramatically to $88.1 \%$ at age 40. For foreigners we find that the retention expectancies are lower for 20 year olds than they are at age zero and at age 40 . For example, foreigners in the UK exhibited retention expectancies of $38.4 \%, 36.7 \%$, and $54.6 \%$ at ages zero, 20 , and 40 years, respectively. The corresponding figures for France are $43.1 \%, 38.2 \%$, and $80.2 \%$, respectively.

\subsection{Summary}

In this section we have shown how different measures of migration provide unique glimpses into patterns of international movement from and to the EU/EFTA, towards both revising and extending current explanations of international migration. The first two measures, foreign-born population stocks and migration rates, are useful for detailing the composition of populations in receiving countries and recent levels of mobility. However, neither of these measures captures the temporal dynamics of international migration produced by the age structure of flows. The expected duration of residence, estimated and extended here, provides an alternative to more conventional measures. Between 2002 and 2007 the EU/EFTA expanded from 19 to 31 countries. Understanding the diverse effects of these expansions is important for considering future expansions, as well as designing policies to deal with issues of increased mobility and the integration of migrants in receiving countries.

Finally, although indirect and susceptible to poor data quality, the retention expectancies for nationals and foreigners in Table 6 demonstrated the importance of 
considering heterogeneous migration flows and the continued need for [harmonized] data to shed light on these dynamics (Ledent 1981; Philipov and Rogers 1981; Rogers and Belanger 1990; Rogers and Raymer 2005). We hope our work provides a starting point for future efforts aimed at elucidating the inherent diversity of international migration flows by echoing prior calls for cross-nationally comparable data on migrant characteristics (Bell et al. 2002).

\section{Discussion and conclusion}

We have provided a descriptive account of the expected duration of international migration in 31 countries in the EU/EFTA each year from 2002 to 2007. A core innovation of this project is the use of harmonized estimates of country-to-country migration flow data available from the MIMOSA project. The issues remedied by these data are serious enough to call into question the host of descriptive and empirical works making use of published sending and receiving countries' reports of international migration, given the lack of a common metric across countries. These data also provide a glimpse into migration patterns from and to countries that fail to report these figures for some or all migration flows.

In 2007 the European Parliament established clear definitions of emigration and immigration. Member states are now required to provide migration flow data to Eurostat (Regulation (EC) No 862 2007). This regulation, however, has not gone far enough to remedy the problem of the incomparability of sending and receiving countries' reports of international migration flows. In particular, the regulations do not stipulate a precise and uniform set of methods for estimating migration flows, or require countries to alter their systems of data collection (Fassman 2009). Until such conventions are implemented, methods for harmonizing and also estimating missing emigration and immigration reports of sending and receiving countries are necessary to ensure that international migration is measured and modelled consistently across countries.

Combining the MIMOSA data with multistate methods, we sought to show that the expected duration of residence of international migration is a unique and useful way to describe country-level migration patterns in conjunction with measures of foreign-born population stocks and migration rates. The measure developed in this project summarizes the temporal dynamics of international migration produced by the age pattern of flows from and to sending and receiving countries, respectively. This feature is particularly important in the European context, where population aging is a serious demographic concern (Bongaarts 2004). Since migrants tend to be younger, they have more potential years of life to be lived in receiving countries, and thus more working 
years. Where issues of international migration intersect with labor market pressures, population aging, and public pensions, it is important that descriptive accounts of country-level migration patterns take into account age-specific migration propensities and the corresponding durations of residence of international migration (Bauer and Zimmerman 1999).

We noted earlier that the measure developed in this project is one way to aid thinking about the context of migrant reception and integration in receiving countries. Migrants who reside in destination countries for longer periods are not necessarily the most highly visible with respect to foreign-born population stocks and migration rates. A large body of theoretical and empirical scholarship has demonstrated positive associations between the proportionate concentration of migrants and various indicators of social exclusion in receiving countries (Blalock 1967; Citrin and Sides 2006; Quillian 1995; Schneider 2008; Semyonov, Raijman and Gorodzeisky 2006). However, little is known about the potential role of the expected duration of residence of international migration at the country-level. Following Ceobanu and Escandell (2010), we suggest that a fruitful extension to the work of this project include empirical efforts to establish or disconfirm the importance of the expected duration of residence as one potential source of cross-country variation in the social exclusion of migrants (see also Pachucki, Pendergrass and Lamont 2007). The efficacy of this measure may yield new insights into societal contexts of migrant reception and incorporation relevant to scholars and policy-makers alike.

\section{Acknowledgements}

Jack DeWaard acknowledges support from NICHD Training Grant T32 HD07014 and Center Grant R24 HD047873 to the Center for Demography and Ecology at the University of Wisconsin-Madison, as well as comments from Theodore P. Gerber, Katherine J. Curtis, Jenna Nobles, Alberto Palloni, James Montgomery, Nico Keilman and Keuntae Kim. James Raymer acknowledges support from the ESRC Research Centre for Population Change (Grant Reference RES-625-28-0001) and previous support from the European Commission/Eurostat tender $n^{\circ}$ 2006/S100 106607 (OJ 27/05/2006). He would also like to thank the other team members of the MIMOSA project for their efforts in producing the harmonized estimates of international migration stocks and flows used in this paper. Both authors are also grateful for the comments of the Editor and two anonymous reviewers. 


\section{References}

Adsera, A. and Chiswick, B.R. (2007). Are there gender and country of origin differences in immigrant labor market outcomes across European destinations? Journal of Population Economics 20(3): 495-526. doi:10.1007/s00148-0060082-y.

Alexander, J.T. (2005). “They're never here more than a year:” Return migration in the southern exodus, 1940-1970. Journal of Social History 38(3): 653-671. doi:10.1353/jsh.2005.0039.

Allport, G. (1954). The Nature of Prejudice. New York: Perseus Books Publishing.

Bauer, T.K. and Zimmermann, K.F. (1999). Assessment of Possible Migration Pressure and its Labour Market Impact Following EU Enlargement to Central and Eastern Europe. Bonn: Institute for the Study of Labor (Research Report No. 3).

Bell, M., Blake, M., Boyle, P., Duke-Williams, O., Rees, P., Stillwell, J., and Hugo, G. (2002). Cross-national comparison of internal migration: Issues and measures. Journal of the Royal Statistical Society Series A (Statistics in Society) 165: 435464. doi:10.1111/1467-985X.00247.

Blalock, H.M. (1967). Toward a theory of minority group relations. New York: Wiley.

Bongaarts, J. (2004). Population Aging and the Rising Cost of Public Pensions. Population Development Review 30(1): 1-23. doi:10.1111/j.1728-4457.2004.000 01.x.

Borjas, G.J., Bronars, S.G. and, Trejo. S.J. (1992). Self-selection and internal migration in the United States. Journal of Urban Economics 32(2): 159-185. doi:10.1016/0094-1190(92)90003-4.

Castles, S. (2007). Twenty-First Century Migration as a Challenge to Sociology. Journal of Ethnic and Migration Studies 33(2): 351-371. doi:10.1080/1369 1830701234491.

Castles, S. and Miller, M. (2003). The Age of Migration: International Population Movements in the Modern World, $3^{\text {rd }}$ edition. New York: The Guilford Press.

Ceobanu, A.M. and Escandell, X. (2010). Comparative analyses of public attitudes toward immigrants and immigration using multinational survey data: A review of theories and research. Annual Review of Sociology 36: 309-328. doi:10.1 146/annurev.soc.012809.102651. 
Citrin, J. and Sides, J. (2006). European immigration in the people's court. In: Parsons, C.A. and Smeeding, T.M. (eds.). Immigration and the Transformation of Europe. Cambridge: Cambridge University Press: 327-361. doi:10.1017/ CBO9780511493577.013.

de Beer, J., Raymer, J., van der Erf, R., and van Wissen., L. (2010). Overcoming the problems of inconsistent international migration data: A new method applied to flows in Europe. European Journal of Population 26(4): 459-481. doi:10.1007/ s10680-010-9220-z.

DeWaard, J., Kim, K., and Raymer, J. (Forthcoming). Migration systems in Europe: Evidence from harmonized flow data. Demography.

Eldridge, H.T. (1965). Primary, secondary, and return migration in the United States, 1955-60. Demography 2: 444-455. doi:10.2307/2060130.

Fassmann, H. (2009). European Migration: Historical Overview and Statistical Problems. In Fassmann, H., Reeger, U., and Sievers, W. (eds). Statistics and Reality: Concepts and Measurements of Migration in Europe. Amsterdam: Amsterdam University Press: 21-44. doi:10.5117/9789089640529.

Herting, J.R., Grusky, D.B., and Van Rompaey, S.E. (1997). The social geography of interstate mobility and persistence. American Sociological Review 62(2): 267287.

Huddleston, T., Niessen, J., Chaoimh, E.N., and White E. (2011). Migrant Integration Policy Index III. Brussels: British Council and Migration Policy Group.

Jennissen, R.P.W. (2004). Macroeconomic Determinants of International Migration in Europe. Amsterdam: Dutch University Press.

Klinthäll, M. (2006). Retirement return migration from Sweden. International Migration 44(2): 153-180. doi:10.1111/j.1468-2435.2006.00367.x.

Kritz, M.M., Lim, L.L., and Zlotnik, H. (1992). International Migration Systems: A Global Approach. Oxford: Clarendon Press.

Kupiszewska, D. and Nowok, B. (2008). Comparability of Statistics on International Migration Flows in the European Union. In: Raymer, J. and Willekens, F. (eds.). International Migration in Europe: Data, Models and Estimates. Chichester: Wiley: 41-72. doi:10.1002/9780470985557.ch3.

Kupiszewska, D., Wiśniowski, A., and Bijak, J. (2009). Estimation of Population Stocks by Country of Birth, Sex and Age for 1st January 2002-2007. The Hague: 
Netherlands Interdisciplinary Demographic Institute (MIMOSA Project Report). http://www-oud.nidi.knaw.nl/en/projects/230211/.

Ledent, J. (1981). Constructing Multiregional Life Tables Using Place-of-Birth-Specific Migration Data. In: Rogers, A. (ed.). Advances in Multiregional Demography. Laxenburg, Austria: International Institute for Applied Systems Analysis. (Research Report 81-6): 35-49.

Long, L. and Hansen, K.A. (1977). Interdivisional Primary, Return and Repeat Migration. Public Data Use 5: 3-10.

Massey, D.S. Arango, J., Hugo, G., Kouaouci, A., Pellegrino, A., and Taylor, J.E. (1998). Worlds in Motion: Understanding International Migration at the End of the Millennium. Oxford: Clarendon Press.

Nowok, B., Kupiszewska, D., and Poulain, M. (2006). Statistics on International Migration Flows. In: Poulain, M., Perrin, N., and Singleton, A. (eds.). THESIM: Towards Harmonised European Statistics on International Migration. Louvainla-Neuve: UCL Presses Universitaires de Louvain: 203-231.

Pachucki, M.A., Pendergrass, S., and Lamont, M. (2007). Boundary processes: Recent theoretical developments and new contributions. Poetics 35(6): 331-351. doi:10.1016/j.poetic.2007.10.001.

Palloni, A. (2001). Increment-Decrement Life Tables. In: Preston, S., Heuveline, P., and Guillot, M. (eds.) Demography: Measuring and Modeling Population Processes. Oxford: Blackwell Publishers: 256-273.

Pettigrew, T.F. (1998). Reactions Toward the new minorities in western Europe. Annual Review of Sociology 24(August): 77-103. doi:10.1146/annurev.soc.24. 1.77 .

Pettigrew, T.F. and Meertens, R.W. (1995). Subtle and Blatant Prejudice in western Europe. European Journal of Social Psychology 25(1): 57-75. doi:10.1002/ejsp. 2420250106.

Philipov, D. and Rogers, A. (1981). Multistate Population Projections. In: Rogers, A. (ed.). Advances in Multiregional Demography. Laxenburg, Austria: International Institute for Applied Systems Analysis. (Research Report 81-6): 51-82.

Pitkin, J. and Myers, D. (2011). A summary period measure of immigrant advancement in the U.S. Demographic Research 24(12): 257-292. doi:10.4054/DemRes. 2011.24.12. 
Poulain, M. (1999). International Migration within Europe: Towards More Complete and Reliable Data? Perugia, Italy: Conference of European Statisticians, Statistical Office of the European Communities (Working Paper No. 37).

Poulain, M. (1993). Confrontation des statistiques de migration intra-Européennes: Vers une matrice complète? European Journal of Population 9(4): 353-381. doi:10.1007/BF01265643.

Poulain, M., Perrin, N., and Singleton, A. (2006). THESIM: Towards Harmonized European Statistics on International Migration. Louvain-la-Neuve: UCL Presses Universitaires de Louvain.

Preston, S.H., Heuveline, P., and Guillot, M. (2001). Demography: Measuring and Modeling Population Processes. Oxford: Blackwell Publishers.

Quillian, L. (1995). Prejudice as a response to perceived group threat: Population composition and anti-immigrant and racial prejudice in Europe. American Sociological Review 60(4): 586-611. doi:10.2307/2096296.

Raymer, J. (2008). Obtaining an Overall Picture of Population Movement in the European Union. In: Raymer, J. and Willekens, F. (eds.). International Migration in Europe: Data, Models and Estimates. Chichester: Wiley: 209-234.

Raymer, J. (2007). The Estimation of International Migration Flows: A General Technique Focused on the Origin-Destination Association Structure. Environment and Planning A, 12: 371-388.

Raymer, J., de Beer, J., and van der Erf, R. (2011). Putting the pieces of the puzzle together: Age and sex-specific estimates of migration amongst countries in the EU/EFTA, 2002-2007. European Journal of Population 27(2): 185-215. doi:10.1007/s10680-011-9230-5.

Raymer, J. Forster, J.J., Smith, P.W.F., Bijak, J., Wiśniowski, A., and. Abel, G.J. (2010). The IMEM Model for Estimating International Migration Flows in the European Union. Geneva: Joint UNECE/Eurostat Work Session on Migration Statistics (Working Paper 14).

Reagan, P.B. and Olsen, R.J. (2000). You can go home again: Evidence from longitudinal data. Demography 37(3): 339-350. doi:10.2307/2648046.

Redstone, I.A., and Massey, D.S. (2004). Coming to stay: An analysis of the U.S. census question on immigrants' year of arrival. Demography 41(4): 721-738. doi:10.1353/dem.2004.0035. 
Regulation (EC) No 862/2007 of the European Parliament and of the Council of 11 July 2007 on Community Statistics on Migration and International Protection and Repealing Council

Regulation (EEC) No 311/76 on the Compilation of Statistics on Foreign Workers. (2007). Official Journal of the European Union. http://eur-lex.europa.eu/ LexUriServ/LexUriServ.do?uri=OJ:L:2007:199:0023:0029:EN:PDF.

Rogers, A. (1975). Introduction to Multiregional Mathematical Demography. New York: Wiley.

Rogers, A. (1995). Multiregional demography: Principles, methods and extensions. London: Wiley.

Rogers, A. and Belanger, A. (1990). The Importance of Place of Birth in Migration and Population Redistribution Analysis. Environment and Planning A 22(2): 193210. doi:10.1068/a220193.

Rogers, A. and Ledent, J. (1976). Increment-decrement life tables: A comment. Demography 13(2): 287-290. doi:10.2307/2060807.

Rogers, A. and Philipov, D. (1979). Multiregional Methods for Subnational Population Projections. Laxenburg, Austria: International Institute for Applied Systems Analysis (Research Report 79-40).

Rogers, A. and Raymer, J. (2005). Origin dependence, secondary migration, and the indirect estimation of migration flows from population stocks. Journal of Population Research 22(1): 1-19. doi:10.1007/BF03031801.

Schlueter, E. and Scheepers, P. (2010). The relationship between outgroup size and anti-outgroup attitudes: A theoretical synthesis and empirical test of group threat and intergroup contact theory. Social Science Research 39(2): 285-295. doi:10.1016/j.ssresearch.2009.07.006.

Schneider, S.L. (2008). Anti-immigrant attitudes in Europe: Out-group size and perceived ethnic threat. European Sociological Review 24(1): 53-67. doi:10.109 3/esr/jcm034.

Schoen, R. (1988). Modeling Multigroup Populations. New York: Pleneum.

Semyonov, M., Raijman, R., and Gorodzeisky, A. (2006). The rise of anti-foreigner sentiment in European societies, 1988-2000. American Sociological Review 71(3): 426-449. doi:10.1177/000312240607100304. 
Tiemeyer, P. and Ulmer, G. (1991). MSLT: A Program for the Computation of Multistate Life Tables. Madison, WI: Center for Demography and Ecology, University of Wisconsin Madison (Working Paper 91-34). http://www.psc.isr. umich.edu/dis/data/demosoft.html.

United Nations. (1998). Recommendations on Statistics of International Migration. New York: Statistics Division, Department of Economic and Social Affairs, United Nations (Statistical Papers Series M, No. 58, Rev. 1).

van Imhoff, E. (2005). LIPRO 4.0. Tutorial. The Hague: Netherlands Interdisciplinary Demographic Institute.

van Imhoff, E. and Keilman, N. (1991). LIPRO 2.0: An Application of a Dynamic Demographic Projection Model to Household Structure in the Netherlands. The Hague: Netherlands Interdisciplinary Demographic Institute (NIDI/CBGS Publications 23).

Vaupel, J.W. and Yashin, A.I. (1985). Heterogeneity's Ruses: Some Surprising Effects of Selection on Population Dynamics. The American Statistician 39(3): 176-185.

Waldorf, B.S. (1994). Assimilation and attachment in the context of international migration: The case of guestworkers in Germany. Papers in Regional Science 73(3): 241-266. doi:10.1111/j.1435-5597.1994.tb00613.x.

Waldorf, B.S. and Esparza A. (1991). A parametric failure time model of international return migration. Papers in Regional Science 70: 419-438. doi:10.1007/ BF01434597.

Willekens, F. (2011). Biograph: Multistate Analysis of Life Histories with R. (unpublished manuscript).

Willekens, F. and Rogers, A. (1978). Spatial Population Analysis: Methods and Computer Programmes. Laxenburg, Austria: International Institute for Applied Systems Analysis (Research Report RR-78-18). 


\section{Appendix}

Table A1: Expected duration of residence (in years) to be lived by a person in receiving country $j$ above age zero given prior residence in country $i$ at age zero: EU/EFTA countries and rest of world, 2002

\begin{tabular}{|c|c|c|c|c|c|c|c|c|c|c|c|c|c|c|}
\hline \multirow{2}{*}{\multicolumn{2}{|c|}{$\begin{array}{l}\text { Sending } \\
\text { Country } i\end{array}$}} & \multicolumn{13}{|c|}{ Receiving Country $j$} \\
\hline & & \multirow{2}{*}{$\begin{array}{c}\text { AT } \\
60.32\end{array}$} & \multirow{2}{*}{$\frac{\mathrm{BE}}{0.06}$} & \multirow{2}{*}{$\begin{array}{c}\text { BG } \\
0.19\end{array}$} & \multirow{2}{*}{$\frac{\mathrm{CH}}{0.43}$} & \multirow{2}{*}{$\frac{\text { CY }}{0.00}$} & \multirow{2}{*}{$\frac{\mathbf{C Z}}{0.10}$} & \multirow{2}{*}{$\begin{array}{c}\mathrm{DE} \\
3.59\end{array}$} & \multirow{2}{*}{$\begin{array}{c}\text { DK } \\
0.09\end{array}$} & \multirow{2}{*}{$\begin{array}{c}\text { EE } \\
0.00\end{array}$} & \multirow{2}{*}{$\frac{\text { ES }}{0.19}$} & \multirow{2}{*}{$\begin{array}{c}\text { FI } \\
0.04\end{array}$} & \multirow{2}{*}{$\begin{array}{c}\mathbf{F R} \\
0.22\end{array}$} & \multirow{2}{*}{$\begin{array}{c}\mathbf{G R} \\
0.12\end{array}$} \\
\hline AT- & Austria & & & & & & & & & & & & & \\
\hline BE- & Belgium & 0.07 & 61.69 & 0.02 & 0.15 & 0.00 & 0.02 & 1.12 & 0.14 & 0.00 & 0.51 & 0.06 & 1.86 & 0.07 \\
\hline BG- & Bulgaria & 0.58 & 0.07 & 53.47 & 0.11 & 0.05 & 0.25 & 3.48 & 0.05 & 0.00 & 3.31 & 0.02 & 0.30 & 0.30 \\
\hline $\mathrm{CH}-$ & Switzerland & 0.52 & 0.18 & 0.05 & 48.43 & 0.01 & 0.07 & 4.31 & 0.27 & 0.00 & 1.53 & 0.13 & 2.53 & 0.14 \\
\hline CY- & Cyprus & 0.08 & 0.11 & 2.06 & 0.14 & 20.13 & 0.03 & 0.80 & 0.02 & 0.01 & 0.31 & 0.05 & 0.42 & 4.95 \\
\hline CZ- & Czech Republic & 0.24 & 0.08 & 0.74 & 0.16 & 0.01 & 41.66 & 1.61 & 0.03 & 0.00 & 0.15 & 0.01 & 0.34 & 0.08 \\
\hline DE- & Germany & 0.38 & 0.13 & 0.18 & 0.60 & 0.01 & 0.05 & 61.93 & 0.10 & 0.01 & 0.34 & 0.04 & 0.54 & 0.49 \\
\hline DK- & Denmark & 0.13 & 0.23 & 0.02 & 0.34 & 0.00 & 0.03 & 1.36 & 57.89 & 0.06 & 0.33 & 0.31 & 0.69 & 0.13 \\
\hline EE- & Estonia & 0.08 & 0.06 & 0.01 & 0.08 & 0.01 & 0.01 & 1.53 & 0.36 & 52.68 & 0.16 & 3.51 & 0.22 & 0.03 \\
\hline ES- & Spain & 0.04 & 0.09 & 0.04 & 0.23 & 0.00 & 0.01 & 0.74 & 0.08 & 0.00 & 70.29 & 0.04 & 0.30 & 0.01 \\
\hline $\mathrm{Fl}-$ & Finland & 0.17 & 0.16 & 0.01 & 0.30 & 0.00 & 0.02 & 1.11 & 0.21 & 0.20 & 0.30 & 66.49 & 0.31 & 0.06 \\
\hline FR- & France & 0.05 & 0.28 & 0.02 & 0.28 & 0.00 & 0.02 & 0.76 & 0.06 & 0.00 & 0.33 & 0.02 & 68.47 & 0.05 \\
\hline GR- & Greece & 0.15 & 0.05 & 0.10 & 0.08 & 0.30 & 0.01 & 3.18 & 0.06 & 0.00 & 0.11 & 0.03 & 0.24 & 65.80 \\
\hline HU- & Hungary & 0.72 & 0.09 & 0.03 & 0.14 & 0.01 & 0.02 & 3.42 & 0.03 & 0.00 & 0.16 & 0.04 & 0.42 & 0.06 \\
\hline IE- & Ireland & 0.10 & 0.32 & 0.04 & 0.34 & 0.01 & 0.03 & 1.18 & 0.18 & 0.01 & 0.63 & 0.12 & 0.91 & 0.09 \\
\hline IS- & Iceland & 0.22 & 0.16 & 0.01 & 0.24 & 0.00 & 0.01 & 2.01 & 9.47 & 0.04 & 0.62 & 0.56 & 0.50 & 0.05 \\
\hline IT- & Italy & 0.10 & 0.15 & 0.01 & 1.03 & 0.00 & 0.02 & 1.14 & 0.04 & 0.00 & 0.29 & 0.02 & 0.37 & 0.04 \\
\hline LI- & Liechtenstein & 1.52 & 0.02 & 0.01 & 1.88 & 0.00 & 0.01 & 4.40 & 1.16 & 0.00 & 0.31 & 0.01 & 1.62 & 0.03 \\
\hline LT- & Lithuania & 0.09 & 0.04 & 0.01 & 0.08 & 0.01 & 0.03 & 2.32 & 0.48 & 0.05 & 0.88 & 0.07 & 0.21 & 0.02 \\
\hline LU- & Luxembourg & 0.36 & 8.07 & 0.03 & 1.67 & 0.00 & 0.01 & 5.64 & 0.56 & 0.00 & 0.49 & 0.27 & 10.02 & 0.20 \\
\hline LV- & Latvia & 0.08 & 0.02 & 0.01 & 0.08 & 0.03 & 0.01 & 1.67 & 0.39 & 0.53 & 0.18 & 0.09 & 0.61 & 0.02 \\
\hline MT- & Malta & 0.04 & 0.14 & 0.02 & 0.11 & 0.02 & 0.01 & 0.57 & 0.07 & 0.00 & 0.08 & 0.01 & 1.35 & 0.04 \\
\hline NL- & Netherlands & 0.13 & 1.65 & 0.02 & 0.33 & 0.00 & 0.04 & 1.92 & 0.13 & 0.00 & 0.47 & 0.06 & 0.72 & 0.10 \\
\hline NO- & Norway & 0.07 & 0.12 & 0.02 & 0.19 & 0.00 & 0.02 & 0.86 & 1.67 & 0.03 & 0.59 & 0.89 & 0.36 & 0.05 \\
\hline PL- & Poland & 0.21 & 0.23 & 0.02 & 0.21 & 0.02 & 0.10 & 5.04 & 0.06 & 0.00 & 0.33 & 0.01 & 0.49 & 0.13 \\
\hline PT- & Portugal & 0.10 & 0.13 & 0.01 & 0.11 & 0.00 & 0.01 & 1.89 & 0.04 & 0.00 & 1.81 & 0.02 & 1.17 & 0.02 \\
\hline RO- & Romania & 0.54 & 0.06 & 0.07 & 0.12 & 0.02 & 0.06 & 2.09 & 0.03 & 0.00 & 5.30 & 0.01 & 0.42 & 0.11 \\
\hline SE- & Sweden & 0.20 & 0.15 & 0.01 & 0.33 & 0.01 & 0.02 & 1.00 & 0.66 & 0.03 & 0.36 & 1.45 & 0.39 & 0.19 \\
\hline SI- & Slovenia & 0.62 & 0.11 & 0.01 & 0.84 & 0.00 & 0.02 & 2.46 & 0.04 & 0.00 & 0.11 & 0.00 & 0.19 & 0.06 \\
\hline SK- & Slovakia & 1.15 & 0.11 & 0.13 & 1.39 & 0.05 & 5.14 & 4.07 & 0.03 & 0.00 & 0.26 & 0.01 & 0.40 & 0.09 \\
\hline UK- & United Kingdom & 0.06 & 0.09 & 0.03 & 0.23 & 0.04 & 0.03 & 0.64 & 0.14 & 0.01 & 0.98 & 0.06 & 1.04 & 0.25 \\
\hline RW- & Rest of World & 0.02 & 0.02 & 0.00 & 0.02 & 0.00 & 0.02 & 0.15 & 0.01 & 0.00 & 0.08 & 0.00 & 0.07 & 0.01 \\
\hline
\end{tabular}


DeWaard \& Raymer: The temporal dynamics of international migration in Europe

Table A1: (Continued)

\begin{tabular}{|c|c|c|c|c|c|c|c|c|c|c|c|c|}
\hline \multirow{2}{*}{\multicolumn{2}{|c|}{$\begin{array}{l}\text { Sending } \\
\text { Country } i\end{array}$}} & \multicolumn{11}{|c|}{ Receiving Country $j$} \\
\hline & & \multirow{2}{*}{$\frac{\mathrm{HU}}{0.53}$} & & & & \multirow{2}{*}{$\frac{\text { LI }}{0.01}$} & \multirow{2}{*}{$\begin{array}{l}\text { LT } \\
0.00\end{array}$} & \multirow{2}{*}{$\frac{\text { LU }}{0.01}$} & \multirow{2}{*}{$\frac{\text { LV }}{0.00}$} & \multirow{2}{*}{$\begin{array}{l}\text { MT } \\
0.00\end{array}$} & \multirow{2}{*}{$\frac{\text { NL }}{0.23}$} & \multirow{2}{*}{$\frac{\text { NO }}{0.03}$} \\
\hline AT- & Austria & & & & & & & & & & & \\
\hline BE- & Belgium & 0.03 & 0.06 & 0.01 & 0.89 & 0.00 & 0.01 & 0.77 & 0.00 & 0.00 & 1.70 & 0.06 \\
\hline BG- & Bulgaria & 0.04 & 0.03 & 0.00 & 0.78 & 0.00 & 0.00 & 0.00 & 0.00 & 0.00 & 0.20 & 0.05 \\
\hline $\mathrm{CH}-$ & Switzerland & 0.07 & 0.10 & 0.01 & 7.18 & 0.01 & 0.01 & 0.09 & 0.00 & 0.01 & 0.65 & 0.11 \\
\hline $\mathrm{CY}-$ & Cyprus & 0.31 & 0.13 & 0.00 & 0.22 & 0.00 & 0.00 & 0.00 & 0.00 & 0.04 & 0.11 & 0.02 \\
\hline CZ- & Czech Republic & 0.04 & 0.04 & 0.00 & 0.16 & 0.00 & 0.00 & 0.00 & 0.00 & 0.00 & 0.10 & 0.02 \\
\hline DE- & Germany & 0.37 & 0.08 & 0.00 & 0.71 & 0.00 & 0.01 & 0.06 & 0.01 & 0.00 & 0.32 & 0.05 \\
\hline DK- & Denmark & 0.05 & 0.13 & 0.36 & 0.33 & 0.00 & 0.08 & 0.03 & 0.04 & 0.00 & 0.32 & 1.65 \\
\hline EE- & Estonia & 0.03 & 0.06 & 0.02 & 0.22 & 0.00 & 0.08 & 0.01 & 0.23 & 0.00 & 0.12 & 0.34 \\
\hline ES- & Spain & 0.01 & 0.05 & 0.00 & 0.24 & 0.00 & 0.00 & 0.01 & 0.00 & 0.00 & 0.19 & 0.04 \\
\hline $\mathrm{FI}-$ & Finland & 0.09 & 0.09 & 0.02 & 0.30 & 0.00 & 0.11 & 0.01 & 0.03 & 0.00 & 0.30 & 0.72 \\
\hline FR- & France & 0.02 & 0.05 & 0.00 & 0.43 & 0.00 & 0.01 & 0.17 & 0.00 & 0.01 & 0.18 & 0.02 \\
\hline GR- & Greece & 0.03 & 0.02 & 0.00 & 0.35 & 0.00 & 0.00 & 0.01 & 0.00 & 0.01 & 0.34 & 0.03 \\
\hline HU- & Hungary & 57.98 & 0.04 & 0.00 & 0.27 & 0.00 & 0.00 & 0.01 & 0.00 & 0.00 & 0.18 & 0.03 \\
\hline IE- & Ireland & 0.03 & 58.53 & 0.00 & 0.39 & 0.00 & 0.01 & 0.01 & 0.00 & 0.01 & 0.48 & 0.04 \\
\hline IS- & Iceland & 0.02 & 0.06 & 43.40 & 0.29 & 0.00 & 0.05 & 0.01 & 0.13 & 0.01 & 0.84 & 4.45 \\
\hline IT- & Italy & 0.02 & 0.02 & 0.00 & 70.89 & 0.00 & 0.00 & 0.02 & 0.00 & 0.01 & 0.12 & 0.01 \\
\hline LI- & Liechtenstein & 0.03 & 0.01 & 0.00 & 0.19 & 57.51 & 0.00 & 0.01 & 0.00 & 0.00 & 0.21 & 0.02 \\
\hline LT- & Lithuania & 0.01 & 0.11 & 0.04 & 0.19 & 0.00 & 56.30 & 0.00 & 0.23 & 0.00 & 0.15 & 0.20 \\
\hline LU- & Luxembourg & 0.15 & 0.31 & 0.04 & 2.14 & 0.00 & 0.00 & 31.38 & 0.00 & 0.01 & 1.06 & 0.06 \\
\hline LV- & Latvia & 0.01 & 0.04 & 0.01 & 0.24 & 0.00 & 0.25 & 0.00 & 52.13 & 0.00 & 0.12 & 0.18 \\
\hline MT- & Malta & 0.02 & 0.13 & 0.00 & 1.39 & 0.00 & 0.00 & 0.00 & 0.00 & 53.58 & 0.27 & 0.08 \\
\hline NL- & Netherlands & 0.06 & 0.09 & 0.01 & 0.35 & 0.00 & 0.01 & 0.03 & 0.00 & 0.00 & 63.02 & 0.08 \\
\hline NO- & Norway & 0.02 & 0.05 & 0.16 & 0.26 & 0.00 & 0.02 & 0.00 & 0.01 & 0.00 & 0.33 & 60.79 \\
\hline PL- & Poland & 0.03 & 0.81 & 0.01 & 0.49 & 0.00 & 0.01 & 0.01 & 0.00 & 0.00 & 0.20 & 0.05 \\
\hline PT- & Portugal & 0.01 & 0.02 & 0.00 & 0.25 & 0.00 & 0.00 & 0.48 & 0.00 & 0.00 & 0.53 & 0.03 \\
\hline RO- & Romania & 0.22 & 0.03 & 0.00 & 3.26 & 0.00 & 0.00 & 0.00 & 0.00 & 0.00 & 0.10 & 0.03 \\
\hline SE- & Sweden & 0.05 & 0.08 & 0.08 & 0.26 & 0.00 & 0.03 & 0.02 & 0.02 & 0.01 & 0.28 & 1.44 \\
\hline SI- & Slovenia & 0.03 & 0.00 & 0.00 & 0.65 & 0.00 & 0.00 & 0.00 & 0.00 & 0.00 & 0.11 & 0.00 \\
\hline SK- & Slovakia & 0.28 & 0.14 & 0.00 & 0.47 & 0.00 & 0.00 & 0.01 & 0.00 & 0.00 & 0.16 & 0.05 \\
\hline UK- & United Kingdom & 0.11 & 0.53 & 0.01 & 0.43 & 0.00 & 0.01 & 0.01 & 0.00 & 0.02 & 0.38 & 0.08 \\
\hline RW- & Rest of World & 0.01 & 0.00 & 0.00 & 0.09 & 0.00 & 0.00 & 0.00 & 0.00 & 0.00 & 0.03 & 0.01 \\
\hline
\end{tabular}


Demographic Research: Volume 26, Article 21

Table A1: (Continued)

\begin{tabular}{|c|c|c|c|c|c|c|c|c|c|c|c|}
\hline \multicolumn{6}{|c|}{ Sending } & \multicolumn{5}{|c|}{ Receiving Country $j$} & \multirow{2}{*}{$\sum_{j} e_{0}^{i j}(i \neq j)$} \\
\hline \multicolumn{2}{|c|}{ Country $i$} & PT & RO & SE & SI & SK & UK & RW & & & \\
\hline AT- & Austria & 0.08 & 0.44 & 0.12 & 0.13 & 0.14 & 0.48 & 7.13 & 75.82 & 60.32 & 15.50 \\
\hline BE- & Belgium & 0.10 & 0.04 & 0.13 & 0.02 & 0.01 & 0.96 & 5.07 & 75.80 & 61.69 & 14.12 \\
\hline BG- & Bulgaria & 0.03 & 0.37 & 0.08 & 0.00 & 0.09 & 0.77 & 7.52 & 72.11 & 53.47 & 18.64 \\
\hline $\mathrm{CH}-$ & Switzerland & 0.15 & 0.10 & 0.33 & 0.20 & 0.08 & 2.21 & 6.75 & 76.60 & 48.43 & 28.17 \\
\hline CY- & Cyprus & 0.02 & 1.59 & 0.14 & 0.00 & 0.01 & 3.79 & 36.31 & 71.93 & 20.13 & 51.79 \\
\hline CZ- & Czech Republic & 0.03 & 0.29 & 0.04 & 0.01 & 0.36 & 0.76 & 25.55 & 72.61 & 41.66 & 30.95 \\
\hline DE- & Germany & 0.27 & 0.35 & 0.11 & 0.05 & 0.04 & 0.68 & 6.39 & 75.75 & 61.93 & 13.82 \\
\hline DK- & Denmark & 0.06 & 0.04 & 2.65 & 0.00 & 0.03 & 1.05 & 6.59 & 75.15 & 57.89 & 17.26 \\
\hline EE- & Estonia & 0.02 & 0.02 & 0.83 & 0.00 & 0.00 & 1.94 & 8.44 & 71.18 & 52.68 & 18.50 \\
\hline ES- & Spain & 0.11 & 0.15 & 0.08 & 0.00 & 0.01 & 0.81 & 3.15 & 76.81 & 70.29 & 6.51 \\
\hline $\mathrm{FI}-$ & Finland & 0.02 & 0.02 & 2.43 & 0.00 & 0.01 & 0.44 & 2.27 & 76.25 & 66.49 & 9.76 \\
\hline FR- & France & 0.16 & 0.05 & 0.05 & 0.00 & 0.01 & 0.85 & 3.85 & 76.35 & 68.47 & 7.87 \\
\hline GR- & Greece & 0.02 & 0.14 & 0.18 & 0.00 & 0.01 & 0.92 & 4.07 & 76.48 & 65.80 & 10.68 \\
\hline $\mathrm{HU}-$ & Hungary & 0.03 & 0.37 & 0.09 & 0.01 & 0.13 & 0.73 & 6.96 & 72.06 & 57.98 & 14.09 \\
\hline IE- & Ireland & 0.07 & 0.10 & 0.25 & 0.00 & 0.01 & 3.21 & 7.45 & 75.35 & 58.53 & 16.82 \\
\hline IS- & Iceland & 0.08 & 0.02 & 4.62 & 0.10 & 0.01 & 2.90 & 4.94 & 76.60 & 43.40 & 33.20 \\
\hline IT- & Italy & 0.03 & 0.07 & 0.04 & 0.02 & 0.01 & 0.32 & 2.49 & 77.44 & 70.89 & 6.55 \\
\hline LI- & Liechtenstein & 0.02 & 0.03 & 0.04 & 0.01 & 0.01 & 0.12 & 6.79 & 76.29 & 57.51 & 18.78 \\
\hline LT- & Lithuania & 0.02 & 0.01 & 0.24 & 0.00 & 0.00 & 1.68 & 7.56 & 71.34 & 56.30 & 15.04 \\
\hline LU- & Luxembourg & 3.89 & 0.10 & 0.50 & 0.01 & 0.01 & 2.79 & 5.60 & 75.69 & 31.38 & 44.32 \\
\hline LV- & Latvia & 0.01 & 0.01 & 0.24 & 0.00 & 0.00 & 1.15 & 11.90 & 70.10 & 52.13 & 17.97 \\
\hline MT- & Malta & 0.03 & 0.02 & 0.17 & 0.03 & 0.00 & 3.05 & 14.06 & 75.32 & 53.58 & 21.74 \\
\hline NL- & Netherlands & 0.14 & 0.03 & 0.17 & 0.01 & 0.02 & 1.11 & 5.05 & 76.05 & 63.02 & 13.03 \\
\hline NO- & Norway & 0.05 & 0.04 & 4.40 & 0.00 & 0.03 & 1.03 & 4.13 & 76.49 & 60.79 & 15.70 \\
\hline PL- & Poland & 0.03 & 0.03 & 0.10 & 0.00 & 0.04 & 2.18 & 4.92 & 73.61 & 57.84 & 15.77 \\
\hline PT- & Portugal & 63.29 & 0.03 & 0.06 & 0.00 & 0.01 & 1.05 & 4.13 & 75.28 & 63.29 & 12.00 \\
\hline RO- & Romania & 0.04 & 50.41 & 0.06 & 0.00 & 0.13 & 0.22 & 8.14 & 71.54 & 50.41 & 21.13 \\
\hline SE- & Sweden & 0.04 & 0.03 & 65.02 & 0.02 & 0.02 & 1.03 & 3.58 & 77.16 & 65.02 & 12.14 \\
\hline SI- & Slovenia & 0.01 & 0.01 & 0.02 & 66.87 & 0.04 & 0.05 & 2.68 & 74.98 & 66.87 & 8.11 \\
\hline SK- & Slovakia & 0.04 & 0.11 & 0.05 & 0.01 & 49.39 & 1.81 & 7.78 & 73.30 & 49.39 & 23.91 \\
\hline UK- & United Kingdom & 0.09 & 0.04 & 0.18 & 0.01 & 0.01 & 62.18 & 7.69 & 75.56 & 62.18 & 13.38 \\
\hline RW- & Rest of World & 0.01 & 0.01 & 0.01 & 0.00 & 0.00 & 0.11 & 56.54 & 57.26 & 56.54 & 0.71 \\
\hline
\end{tabular}

Source: Authors' calculations

Notes: The expected duration of residence of international migration is a conditional life expectancy at age zero, defined as the average number of years that a person is expected to live in the receiving country $j$ above age zero given prior residence in country $i$ at age zero (Willekens and Rogers 1978; see also Palloni 2001).

$e_{0}^{i^{*}}=$ Total life expectancy above age zero in sending country $i$

$e_{0}^{i i}=$ Average number of years a person can expect to live beyond age zero in country $i$ given prior residence in country $i$ at exact aqe zero

$\sum e_{0}^{i j}(i \neq j)=$ Average number of years a person can expect to live beyond age zero in any country but $i$ given prior residence in country $i$ at exact age zero 
DeWaard \& Raymer: The temporal dynamics of international migration in Europe

Table A2: Expected duration of residence (in years) to be lived by a person in receiving country $j$ above age zero given prior residence in country $i$ at age zero: EU/EFTA countries and rest of world, 2004

\begin{tabular}{|c|c|c|c|c|c|c|c|c|c|c|c|c|c|c|}
\hline \multirow{2}{*}{\multicolumn{2}{|c|}{$\begin{array}{l}\text { Sending } \\
\text { Country } i\end{array}$}} & \multicolumn{13}{|c|}{ Receiving Country $j$} \\
\hline & & \multirow{2}{*}{$\frac{\text { AT }}{55.78}$} & \multirow{2}{*}{$\frac{\text { BE }}{0.08}$} & \multirow{2}{*}{$\frac{\text { BG }}{0.33}$} & \multirow{2}{*}{$\frac{\mathrm{CH}}{0.41}$} & \multirow{2}{*}{$\frac{\text { CY }}{0.01}$} & \multirow{2}{*}{$\frac{\text { CZ }}{0.12}$} & \multirow{2}{*}{$\frac{\mathrm{DE}}{3.28}$} & \multirow{2}{*}{$\frac{\text { DK }}{0.07}$} & \multirow{2}{*}{$\frac{\mathrm{EE}}{0.00}$} & \multirow{2}{*}{$\begin{array}{l}\text { ES } \\
0.33\end{array}$} & \multirow{2}{*}{$\frac{\mathrm{FI}}{0.04}$} & \multirow{2}{*}{$\frac{\mathbf{F R}}{0.29}$} & \multirow{2}{*}{$\frac{\text { GR }}{0.1}$} \\
\hline AT- & Austria & & & & & & & & & & & & & \\
\hline BE- & Belgium & 0.12 & 60.84 & 0.02 & 0.14 & 0.01 & 0.02 & 1.10 & 0.12 & 0.00 & 0.70 & 0.07 & 2.17 & 0.07 \\
\hline BG- & Bulgaria & 0.67 & 0.08 & 50.98 & 0.12 & 0.09 & 0.27 & 3.02 & 0.04 & 0.00 & 4.32 & 0.03 & 0.37 & 0.33 \\
\hline $\mathrm{CH}-$ & Switzerland & 0.71 & 0.19 & 0.06 & 48.75 & 0.01 & 0.08 & 4.33 & 0.28 & 0.01 & 1.94 & 0.19 & 2.89 & 0.16 \\
\hline CY- & $\begin{array}{l}\text { Cyprus } \\
\text { Czech }\end{array}$ & 0.09 & 0.11 & 1.79 & 0.12 & 22.13 & 0.04 & 0.73 & 0.02 & 0.01 & 0.44 & 0.06 & 0.41 & 4.49 \\
\hline CZ- & Republic & 0.33 & 0.09 & 0.76 & 0.15 & 0.01 & 39.68 & 1.42 & 0.04 & 0.00 & 0.23 & 0.01 & 0.37 & 0.08 \\
\hline DE- & Germany & 0.60 & 0.14 & 0.20 & 0.58 & 0.01 & 0.06 & 60.18 & 0.10 & 0.02 & 0.48 & 0.05 & 0.58 & 0.51 \\
\hline DK- & Denmark & 0.16 & 0.20 & 0.03 & 0.32 & 0.01 & 0.03 & 1.30 & 56.62 & 0.05 & 0.47 & 0.33 & 0.69 & 0.11 \\
\hline EE- & Estonia & 0.14 & 0.07 & 0.01 & 0.08 & 0.03 & 0.02 & 1.33 & 0.25 & 51.57 & 0.24 & 4.71 & 0.26 & 0.03 \\
\hline ES- & Spain & 0.06 & 0.14 & 0.06 & 0.30 & 0.00 & 0.01 & 0.74 & 0.08 & 0.00 & 67.52 & 0.05 & 0.48 & 0.02 \\
\hline $\mathrm{FI}-$ & Finland & 0.21 & 0.18 & 0.01 & 0.23 & 0.01 & 0.02 & 1.10 & 0.20 & 0.48 & 0.40 & 66.33 & 0.36 & 0.07 \\
\hline FR- & France & 0.06 & 0.33 & 0.02 & 0.27 & 0.00 & 0.02 & 0.74 & 0.06 & 0.00 & 0.45 & 0.02 & 67.87 & 0.05 \\
\hline GR- & Greece & 0.15 & 0.06 & 0.12 & 0.07 & 0.52 & 0.02 & 2.22 & 0.06 & 0.00 & 0.16 & 0.03 & 0.27 & 66.24 \\
\hline HU- & Hungary & 0.91 & 0.10 & 0.04 & 0.14 & 0.02 & 0.04 & 3.46 & 0.05 & 0.00 & 0.22 & 0.04 & 0.49 & 0.06 \\
\hline IE- & Ireland & 0.12 & 0.40 & 0.05 & 0.35 & 0.02 & 0.04 & 0.90 & 0.12 & 0.01 & 0.84 & 0.07 & 1.14 & 0.11 \\
\hline IS- & Iceland & 0.21 & 0.12 & 0.01 & 0.20 & 0.01 & 0.03 & 1.84 & 9.69 & 0.03 & 0.85 & 0.52 & 0.46 & 0.05 \\
\hline IT- & Italy & 0.11 & 0.17 & 0.01 & 1.01 & 0.00 & 0.02 & 0.93 & 0.04 & 0.00 & 0.38 & 0.02 & 0.47 & 0.04 \\
\hline LI- & Liechtenstein & 5.12 & 0.02 & 0.03 & 1.82 & 0.00 & 0.02 & 3.64 & 0.28 & 0.00 & 0.55 & 0.09 & 2.06 & 0.04 \\
\hline LT- & Lithuania & 0.17 & 0.16 & 0.05 & 0.22 & 0.01 & 0.04 & 2.82 & 0.54 & 0.05 & 1.26 & 0.10 & 0.44 & 0.08 \\
\hline LU- & Luxembourg & 0.36 & 8.86 & 0.04 & 1.30 & 0.01 & 0.02 & 5.95 & 0.58 & 0.02 & 0.68 & 0.32 & 10.35 & 0.16 \\
\hline LV- & Latvia & 0.14 & 0.06 & 0.01 & 0.17 & 0.05 & 0.01 & 1.80 & 0.31 & 0.32 & 0.24 & 0.11 & 0.25 & 0.03 \\
\hline MT- & Malta & 0.05 & 0.17 & 0.02 & 0.11 & 0.04 & 0.01 & 0.44 & 0.04 & 0.00 & 0.13 & 0.01 & 1.57 & 0.04 \\
\hline NL- & Netherlands & 0.17 & 1.68 & 0.02 & 0.25 & 0.01 & 0.05 & 1.80 & 0.12 & 0.00 & 0.65 & 0.07 & 0.74 & 0.11 \\
\hline NO- & Norway & 0.09 & 0.10 & 0.02 & 0.14 & 0.00 & 0.02 & 0.79 & 1.53 & 0.04 & 0.80 & 0.83 & 0.33 & 0.05 \\
\hline PL- & Poland & 0.55 & 0.18 & 0.03 & 0.17 & 0.03 & 0.11 & 6.66 & 0.08 & 0.00 & 0.47 & 0.02 & 0.41 & 0.12 \\
\hline PT- & Portugal & 0.10 & 0.16 & 0.02 & 0.11 & 0.00 & 0.01 & 1.36 & 0.05 & 0.00 & 2.39 & 0.02 & 1.38 & 0.02 \\
\hline RO- & Romania & 0.60 & 0.08 & 0.07 & 0.16 & 0.03 & 0.07 & 1.90 & 0.03 & 0.00 & 6.39 & 0.01 & 0.47 & 0.11 \\
\hline SE- & Sweden & 0.19 & 0.13 & 0.01 & 0.28 & 0.02 & 0.03 & 1.01 & 0.84 & 0.04 & 0.49 & 1.60 & 0.42 & 0.19 \\
\hline SI- & Slovenia & 0.94 & 0.20 & 0.01 & 0.51 & 0.00 & 0.03 & 2.53 & 0.03 & 0.00 & 0.15 & 0.00 & 0.24 & 0.02 \\
\hline SK- & $\begin{array}{l}\text { Slovakia } \\
\text { United }\end{array}$ & 1.49 & 0.11 & 0.12 & 1.17 & 0.09 & 5.24 & 3.52 & 0.04 & 0.00 & 0.30 & 0.01 & 0.38 & 0.08 \\
\hline UK- & Kingdom & 0.08 & 0.09 & 0.03 & 0.20 & 0.08 & 0.03 & 0.56 & 0.13 & 0.01 & 1.33 & 0.06 & 1.05 & 0.26 \\
\hline RW- & Rest of World & 0.03 & 0.02 & 0.00 & 0.02 & 0.00 & 0.02 & 0.11 & 0.01 & 0.00 & 0.10 & 0.00 & 0.07 & 0.01 \\
\hline
\end{tabular}


Table A2: (Continued)

\begin{tabular}{|c|c|c|c|c|c|c|c|c|c|c|c|c|}
\hline \multirow{2}{*}{\multicolumn{2}{|c|}{$\begin{array}{l}\text { Sending } \\
\text { Country } i \\
\end{array}$}} & \multicolumn{11}{|c|}{ Receiving Country $j$} \\
\hline & & \multirow{2}{*}{$\frac{\mathrm{HU}}{1.36}$} & & & & & \multirow{2}{*}{$\frac{\mathbf{L T}}{0.02}$} & \multirow{2}{*}{$\frac{\text { LU }}{0.02}$} & \multirow{2}{*}{$\frac{\text { LV }}{0.00}$} & \multirow{2}{*}{$\frac{\text { MT }}{0.00}$} & \multirow{2}{*}{$\frac{\mathrm{NL}}{0.20}$} & \multirow{2}{*}{$\frac{\text { NO }}{0.04}$} \\
\hline AT- & Austria & & & & & & & & & & & \\
\hline BE- & Belgium & 0.04 & 0.07 & 0.00 & 0.61 & 0.00 & 0.01 & 0.75 & 0.00 & 0.00 & 1.63 & 0.05 \\
\hline BG- & Bulgaria & 0.06 & 0.04 & 0.00 & 2.11 & 0.00 & 0.03 & 0.01 & 0.00 & 0.00 & 0.19 & 0.04 \\
\hline $\mathrm{CH}-$ & Switzerland & 0.12 & 0.13 & 0.01 & 4.36 & 0.01 & 0.02 & 0.09 & 0.01 & 0.01 & 0.55 & 0.10 \\
\hline CY- & Cyprus & 0.79 & 0.13 & 0.00 & 0.56 & 0.00 & 0.01 & 0.00 & 0.00 & 0.04 & 0.14 & 0.03 \\
\hline CZ- & Czech Republic & 0.08 & 0.05 & 0.00 & 0.37 & 0.00 & 0.01 & 0.00 & 0.00 & 0.00 & 0.13 & 0.02 \\
\hline DE- & Germany & 0.72 & 0.08 & 0.01 & 0.85 & 0.00 & 0.04 & 0.06 & 0.01 & 0.00 & 0.35 & 0.06 \\
\hline DK- & Denmark & 0.09 & 0.12 & 0.42 & 0.32 & 0.00 & 0.09 & 0.02 & 0.07 & 0.00 & 0.31 & 1.50 \\
\hline EE- & Estonia & 0.06 & 0.08 & 0.02 & 0.38 & 0.00 & 0.09 & 0.04 & 0.41 & 0.00 & 0.33 & 0.30 \\
\hline ES- & Spain & 0.02 & 0.08 & 0.00 & 0.26 & 0.00 & 0.03 & 0.01 & 0.00 & 0.00 & 0.21 & 0.04 \\
\hline FI- & Finland & 0.14 & 0.11 & 0.02 & 0.24 & 0.00 & 0.06 & 0.00 & 0.07 & 0.00 & 0.25 & 0.38 \\
\hline FR- & France & 0.03 & 0.07 & 0.00 & 0.32 & 0.00 & 0.01 & 0.17 & 0.00 & 0.01 & 0.16 & 0.02 \\
\hline GR- & Greece & 0.04 & 0.03 & 0.00 & 0.28 & 0.00 & 0.01 & 0.01 & 0.00 & 0.01 & 0.28 & 0.02 \\
\hline HU- & Hungary & 57.27 & 0.05 & 0.00 & 0.34 & 0.00 & 0.00 & 0.01 & 0.00 & 0.00 & 0.20 & 0.02 \\
\hline IE- & Ireland & 0.05 & 56.80 & 0.00 & 0.48 & 0.00 & 0.18 & 0.02 & 0.03 & 0.01 & 0.34 & 0.05 \\
\hline IS- & Iceland & 0.02 & 0.07 & 42.68 & 0.38 & 0.00 & 0.06 & 0.01 & 0.02 & 0.00 & 0.70 & 2.29 \\
\hline IT- & Italy & 0.03 & 0.05 & 0.00 & 71.09 & 0.00 & 0.01 & 0.02 & 0.00 & 0.00 & 0.11 & 0.01 \\
\hline LI- & Liechtenstein & 0.16 & 0.01 & 0.00 & 0.57 & 54.17 & 0.00 & 0.01 & 0.00 & 0.00 & 0.04 & 0.01 \\
\hline LT- & Lithuania & 0.02 & 1.44 & 0.08 & 0.62 & 0.00 & 49.67 & 0.01 & 0.43 & 0.00 & 0.40 & 0.37 \\
\hline LU- & Luxembourg & 0.08 & 0.38 & 0.04 & 1.31 & 0.00 & 0.01 & 30.12 & 0.00 & 0.00 & 0.91 & 0.07 \\
\hline LV- & Latvia & 0.01 & 0.24 & 0.03 & 0.33 & 0.00 & 0.20 & 0.01 & 55.19 & 0.00 & 0.18 & 0.13 \\
\hline MT- & Malta & 0.06 & 0.17 & 0.00 & 0.76 & 0.00 & 0.00 & 0.01 & 0.00 & 52.08 & 0.32 & 0.01 \\
\hline NL- & Netherlands & 0.10 & 0.11 & 0.01 & 0.32 & 0.00 & 0.01 & 0.03 & 0.00 & 0.01 & 61.58 & 0.10 \\
\hline NO- & Norway & 0.04 & 0.05 & 0.15 & 0.17 & 0.00 & 0.11 & 0.00 & 0.03 & 0.00 & 0.33 & 61.98 \\
\hline PL- & Poland & 0.02 & 0.61 & 0.05 & 1.18 & 0.00 & 0.02 & 0.01 & 0.01 & 0.00 & 0.40 & 0.10 \\
\hline PT- & Portugal & 0.01 & 0.03 & 0.01 & 0.21 & 0.00 & 0.02 & 0.51 & 0.00 & 0.00 & 0.42 & 0.03 \\
\hline RO- & Romania & 0.42 & 0.04 & 0.00 & 9.23 & 0.00 & 0.00 & 0.01 & 0.00 & 0.00 & 0.10 & 0.02 \\
\hline SE- & Sweden & 0.10 & 0.09 & 0.09 & 0.24 & 0.00 & 0.05 & 0.02 & 0.03 & 0.01 & 0.26 & 1.36 \\
\hline SI- & Slovenia & 0.08 & 0.02 & 0.00 & 0.62 & 0.00 & 0.00 & 0.01 & 0.00 & 0.00 & 0.13 & 0.01 \\
\hline SK- & Slovakia & 0.52 & 0.13 & 0.01 & 0.57 & 0.00 & 0.01 & 0.01 & 0.00 & 0.00 & 0.23 & 0.05 \\
\hline UK- & United Kingdom & 0.18 & 0.53 & 0.01 & 0.38 & 0.00 & 0.05 & 0.01 & 0.01 & 0.02 & 0.30 & 0.08 \\
\hline RW- & Rest of World & 0.01 & 0.01 & 0.00 & 0.18 & 0.00 & 0.00 & 0.00 & 0.00 & 0.00 & 0.02 & 0.01 \\
\hline
\end{tabular}


DeWaard \& Raymer: The temporal dynamics of international migration in Europe

\section{Table A2: (Continued)}

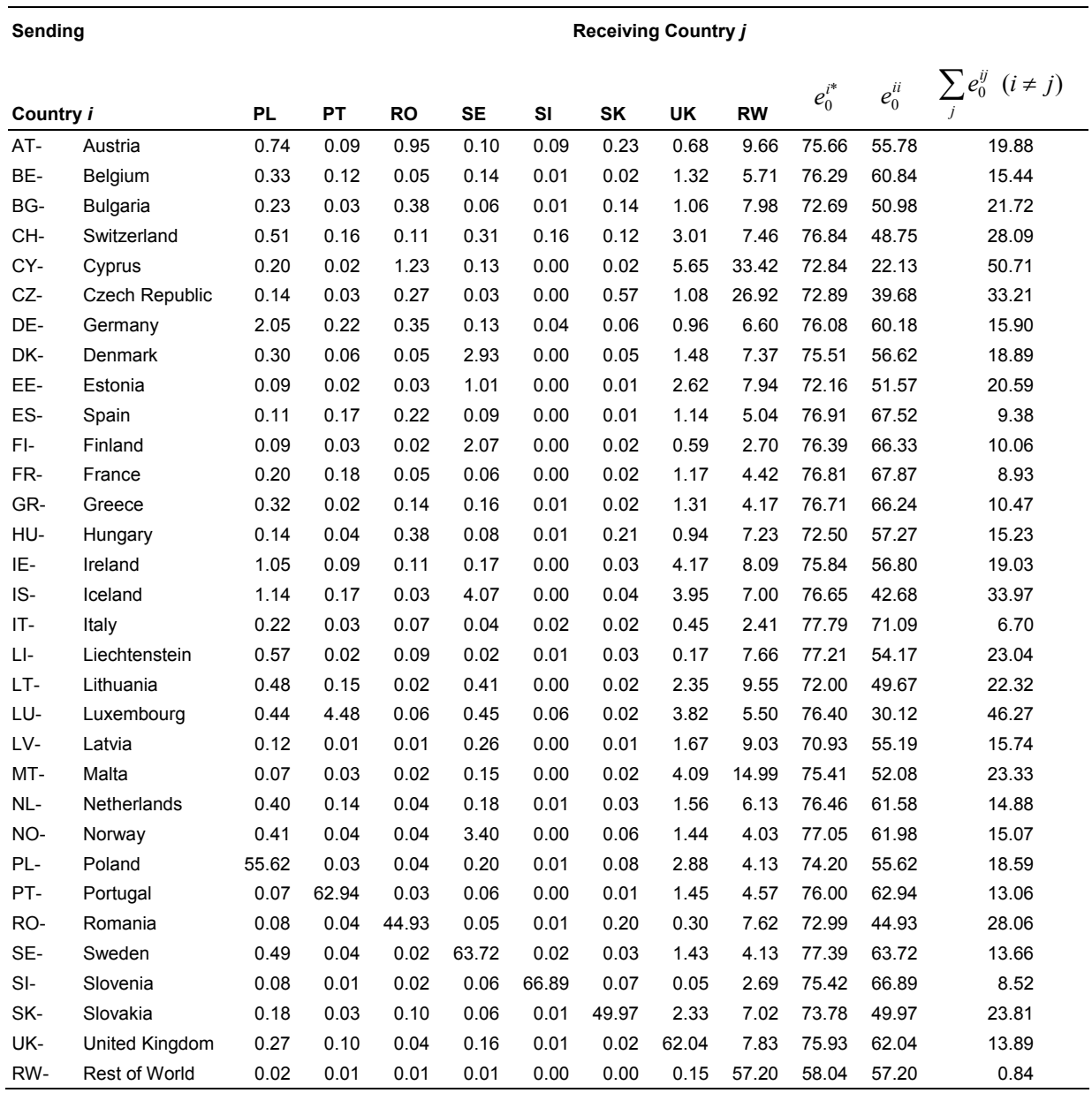

Source: Authors' calculations

Notes: The expected duration of residence of international migration is a conditional life expectancy at age zero, defined as the average number of years that a person is expected to live in the receiving country $j$ above age zero given prior residence in $i^{*} \quad$ country $i$ at age zero (Willekens and Rogers 1978; see also Palloni 2001).

$e_{0}^{i *} \quad=$ Total life expectancy above age zero in sending country $i$

$e_{0}^{i i} \quad=$ Average number of years a person can expect to live beyond age zero in country $i$ given prior residence in country $i$ at exact age zero $\begin{aligned} \sum_{j} e_{0}^{i j}(i \neq j) \quad= & \text { Average number of years a person can expect to live beyond age zero in any country but } i \text { given prior residence in } \\ & \text { country } i \text { at exact age zero }\end{aligned}$ 
Table A3: Expected Duration of Residence (in Years) to be Lived by a Person in Receiving Country $\boldsymbol{j}$ Above Age Zero Given Prior Residence in Country $i$ at Age Zero: EU/EFTA Countries and Rest of World, 2006

\begin{tabular}{|c|c|c|c|c|c|c|c|c|c|c|c|c|c|c|}
\hline \multirow{2}{*}{\multicolumn{2}{|c|}{$\begin{array}{l}\text { Sending } \\
\text { Country } i\end{array}$}} & \multicolumn{13}{|c|}{ Receiving Country $j$} \\
\hline & & \multirow{2}{*}{$\frac{\text { AT }}{52.19}$} & \multirow{2}{*}{$\frac{\mathrm{BE}}{0.12}$} & \multirow{2}{*}{$\frac{\text { BG }}{0.34}$} & \multirow{2}{*}{$\frac{\mathrm{CH}}{0.65}$} & \multirow{2}{*}{$\frac{\text { CY }}{0.01}$} & \multirow{2}{*}{$\frac{C Z}{0.20}$} & \multirow{2}{*}{$\frac{\mathrm{DE}}{3.48}$} & \multirow{2}{*}{$\frac{\text { DK }}{0.09}$} & \multirow{2}{*}{$\frac{\mathrm{EE}}{0.01}$} & \multirow{2}{*}{$\frac{\text { ES }}{0.41}$} & \multirow{2}{*}{$\frac{\mathbf{F I}}{0.05}$} & \multirow{2}{*}{$\frac{\text { FR }}{0.40}$} & \multirow{2}{*}{$\frac{\text { GR }}{0.19}$} \\
\hline AT- & Austria & & & & & & & & & & & & & \\
\hline BE- & Belgium & 0.10 & 58.79 & 0.03 & 0.14 & 0.01 & 0.04 & 1.03 & 0.12 & 0.00 & 0.79 & 0.08 & 2.58 & 0.08 \\
\hline BG- & Bulgaria & 0.48 & 0.11 & 49.29 & 0.14 & 0.06 & 0.37 & 2.01 & 0.04 & 0.00 & 4.99 & 0.02 & 0.50 & 0.38 \\
\hline $\mathrm{CH}-$ & Switzerland & 0.67 & 0.23 & 0.07 & 45.78 & 0.01 & 0.12 & 4.48 & 0.29 & 0.01 & 2.10 & 0.18 & 3.32 & 0.16 \\
\hline CY- & Cyprus & 0.07 & 0.11 & 1.80 & 0.11 & 21.60 & 0.05 & 0.64 & 0.04 & 0.01 & 0.52 & 0.05 & 0.44 & 4.65 \\
\hline CZ- & Czech Republic & 0.31 & 0.09 & 0.73 & 0.16 & 0.01 & 38.39 & 1.29 & 0.05 & 0.00 & 0.27 & 0.02 & 0.39 & 0.08 \\
\hline DE- & Germany & 0.68 & 0.14 & 0.15 & 0.64 & 0.01 & 0.09 & 61.01 & 0.13 & 0.01 & 0.56 & 0.05 & 0.53 & 0.40 \\
\hline DK- & Denmark & 0.14 & 0.19 & 0.03 & 0.25 & 0.01 & 0.06 & 1.25 & 55.46 & 0.04 & 0.54 & 0.33 & 0.58 & 0.10 \\
\hline EE- & Estonia & 0.10 & 0.08 & 0.01 & 0.08 & 0.02 & 0.03 & 0.97 & 0.30 & 49.88 & 0.28 & 6.79 & 0.30 & 0.03 \\
\hline ES- & Spain & 0.06 & 0.32 & 0.15 & 0.57 & 0.00 & 0.02 & 0.70 & 0.09 & 0.00 & 58.23 & 0.06 & 1.12 & 0.04 \\
\hline FI- & Finland & 0.21 & 0.14 & 0.01 & 0.22 & 0.00 & 0.04 & 0.99 & 0.23 & 0.37 & 0.46 & 67.31 & 0.29 & 0.04 \\
\hline FR- & France & 0.06 & 0.41 & 0.03 & 0.28 & 0.00 & 0.03 & 0.76 & 0.07 & 0.00 & 0.52 & 0.03 & 66.32 & 0.06 \\
\hline GR- & Greece & 0.12 & 0.07 & 0.12 & 0.07 & 0.37 & 0.03 & 1.84 & 0.05 & 0.00 & 0.18 & 0.03 & 0.30 & 66.32 \\
\hline $\mathrm{HU}-$ & Hungary & 1.02 & 0.12 & 0.05 & 0.16 & 0.02 & 0.09 & 3.60 & 0.07 & 0.00 & 0.27 & 0.03 & 0.59 & 0.07 \\
\hline IE- & Ireland & 0.10 & 0.52 & 0.06 & 0.37 & 0.02 & 0.05 & 0.90 & 0.12 & 0.01 & 0.92 & 0.10 & 1.47 & 0.13 \\
\hline IS- & Iceland & 0.28 & 0.15 & 0.01 & 0.19 & 0.00 & 0.05 & 1.50 & 9.02 & 0.05 & 0.95 & 0.77 & 0.55 & 0.05 \\
\hline IT- & Italy & 0.10 & 0.17 & 0.02 & 0.80 & 0.00 & 0.03 & 0.85 & 0.05 & 0.00 & 0.44 & 0.02 & 0.45 & 0.04 \\
\hline LI- & Liechtenstein & 2.46 & 0.03 & 0.02 & 1.62 & 0.00 & 0.04 & 3.32 & 0.25 & 0.00 & 0.62 & 0.01 & 2.21 & 0.03 \\
\hline LT- & Lithuania & 0.22 & 0.15 & 0.08 & 0.12 & 0.01 & 0.05 & 2.84 & 0.81 & 0.04 & 1.50 & 0.12 & 0.46 & 0.07 \\
\hline LU- & Luxembourg & 0.37 & 8.03 & 0.03 & 1.03 & 0.00 & 0.02 & 7.15 & 0.48 & 0.02 & 0.73 & 0.29 & 9.98 & 0.13 \\
\hline LV- & Latvia & 0.08 & 0.09 & 0.01 & 0.18 & 0.03 & 0.02 & 1.51 & 0.41 & 0.41 & 0.31 & 0.15 & 0.79 & 0.04 \\
\hline MT- & Malta & 0.07 & 0.20 & 0.02 & 0.10 & 0.02 & 0.02 & 0.70 & 0.12 & 0.00 & 0.17 & 0.01 & 1.76 & 0.05 \\
\hline NL- & Netherlands & 0.18 & 2.07 & 0.03 & 0.31 & 0.01 & 0.07 & 1.90 & 0.13 & 0.01 & 0.75 & 0.07 & 0.84 & 0.14 \\
\hline NO- & Norway & 0.08 & 0.12 & 0.03 & 0.14 & 0.00 & 0.04 & 0.70 & 1.49 & 0.03 & 0.92 & 0.60 & 0.32 & 0.06 \\
\hline PL- & Poland & 0.43 & 0.39 & 0.04 & 0.28 & 0.02 & 0.15 & 7.03 & 0.19 & 0.00 & 0.53 & 0.03 & 0.84 & 0.22 \\
\hline PT- & Portugal & 0.10 & 0.18 & 0.02 & 0.12 & 0.00 & 0.01 & 1.24 & 0.06 & 0.00 & 2.75 & 0.03 & 1.64 & 0.02 \\
\hline RO- & Romania & 0.48 & 0.10 & 0.09 & 0.15 & 0.02 & 0.12 & 1.75 & 0.03 & 0.00 & 6.94 & 0.02 & 0.55 & 0.11 \\
\hline SE- & Sweden & 0.22 & 0.16 & 0.01 & 0.28 & 0.01 & 0.04 & 0.92 & 0.93 & 0.05 & 0.56 & 1.51 & 0.48 & 0.25 \\
\hline SI- & Slovenia & 0.98 & 0.25 & 0.01 & 0.65 & 0.00 & 0.05 & 1.30 & 0.05 & 0.00 & 0.19 & 0.01 & 0.22 & 0.01 \\
\hline SK- & Slovakia & 1.46 & 0.20 & 0.17 & 1.80 & 0.06 & 6.16 & 3.40 & 0.06 & 0.00 & 0.39 & 0.01 & 0.68 & 0.13 \\
\hline UK- & United Kingdom & 0.08 & 0.11 & 0.04 & 0.20 & 0.05 & 0.04 & 0.55 & 0.12 & 0.01 & 1.48 & 0.07 & 1.20 & 0.30 \\
\hline RW- & Rest of World & 0.02 & 0.02 & 0.00 & 0.02 & 0.00 & 0.02 & 0.08 & 0.01 & 0.00 & 0.12 & 0.01 & 0.09 & 0.01 \\
\hline
\end{tabular}


DeWaard \& Raymer: The temporal dynamics of international migration in Europe

Table A3: (Continued)

\begin{tabular}{|c|c|c|c|c|c|c|c|c|c|c|c|c|}
\hline \multirow{2}{*}{$\begin{array}{l}\text { Sending } \\
\text { Country } i\end{array}$} & \multicolumn{12}{|c|}{ Receiving Country $j$} \\
\hline & GR & HU & IE & IS & IT & LI & LT & LU & LV & MT & NL & NO \\
\hline AT- Austria & 0.19 & 0.98 & 0.08 & 0.01 & 0.61 & 0.03 & 0.01 & 0.01 & 0.01 & 0.00 & 0.22 & 0.05 \\
\hline BE- Belgium & 0.08 & 0.04 & 0.10 & 0.01 & 0.72 & 0.00 & 0.02 & 0.56 & 0.02 & 0.00 & 1.77 & 0.06 \\
\hline BG- Bulgaria & 0.38 & 0.05 & 0.06 & 0.00 & 1.61 & 0.00 & 0.02 & 0.00 & 0.00 & 0.00 & 0.19 & 0.04 \\
\hline $\mathrm{CH}$ - Switzerland & 0.16 & 0.10 & 0.17 & 0.01 & 5.15 & 0.01 & 0.03 & 0.04 & 0.02 & 0.01 & 0.58 & 0.13 \\
\hline CY- Cyprus & 4.65 & 0.32 & 0.13 & 0.00 & 0.44 & 0.00 & 0.02 & 0.00 & 0.00 & 0.04 & 0.16 & 0.03 \\
\hline CZ- Czech Republic & 0.08 & 0.05 & 0.05 & 0.00 & 0.32 & 0.00 & 0.01 & 0.00 & 0.01 & 0.00 & 0.14 & 0.03 \\
\hline DE- Germany & 0.40 & 0.35 & 0.09 & 0.01 & 0.81 & 0.00 & 0.04 & 0.06 & 0.02 & 0.00 & 0.41 & 0.10 \\
\hline DK- Denmark & 0.10 & 0.09 & 0.12 & 0.57 & 0.31 & 0.00 & 0.07 & 0.03 & 0.07 & 0.01 & 0.33 & 1.48 \\
\hline EE- Estonia & 0.03 & 0.04 & 0.10 & 0.03 & 0.32 & 0.00 & 0.06 & 0.01 & 0.40 & 0.00 & 0.19 & 0.45 \\
\hline ES- Spain & 0.04 & 0.03 & 0.18 & 0.00 & 0.32 & 0.00 & 0.04 & 0.01 & 0.00 & 0.00 & 0.23 & 0.05 \\
\hline FI- Finland & 0.04 & 0.04 & 0.16 & 0.02 & 0.26 & 0.00 & 0.03 & 0.01 & 0.06 & 0.01 & 0.24 & 0.36 \\
\hline FR- France & 0.06 & 0.03 & 0.09 & 0.00 & 0.37 & 0.00 & 0.01 & 0.15 & 0.00 & 0.01 & 0.19 & 0.03 \\
\hline GR- Greece & 66.32 & 0.03 & 0.04 & 0.00 & 0.31 & 0.00 & 0.01 & 0.01 & 0.00 & 0.01 & 0.35 & 0.03 \\
\hline HU- Hungary & 0.07 & 55.26 & 0.07 & 0.00 & 0.34 & 0.00 & 0.00 & 0.01 & 0.00 & 0.00 & 0.19 & 0.04 \\
\hline IE- Ireland & 0.13 & 0.05 & 54.29 & 0.00 & 0.40 & 0.00 & 0.70 & 0.03 & 0.14 & 0.01 & 0.30 & 0.05 \\
\hline IS- Iceland & 0.05 & 0.02 & 0.09 & 41.45 & 0.48 & 0.00 & 0.12 & 0.01 & 0.09 & 0.01 & 0.51 & 2.29 \\
\hline IT- Italy & 0.04 & 0.02 & 0.04 & 0.00 & 71.35 & 0.00 & 0.01 & 0.01 & 0.00 & 0.01 & 0.12 & 0.02 \\
\hline LI- Liechtenstein & 0.03 & 0.04 & 0.02 & 0.00 & 0.77 & 55.64 & 0.00 & 0.01 & 0.00 & 0.00 & 0.04 & 0.01 \\
\hline LT- Lithuania & 0.07 & 0.02 & 1.89 & 0.12 & 0.52 & 0.00 & 49.05 & 0.01 & 0.52 & 0.00 & 0.28 & 0.97 \\
\hline LU- Luxembourg & 0.13 & 0.11 & 0.22 & 0.05 & 1.44 & 0.00 & 0.06 & 32.27 & 0.02 & 0.00 & 0.93 & 0.06 \\
\hline LV- Latvia & 0.04 & 0.03 & 0.85 & 0.04 & 0.33 & 0.00 & 0.26 & 0.01 & 47.04 & 0.00 & 0.15 & 0.29 \\
\hline MT- Malta & 0.05 & 0.03 & 0.21 & 0.00 & 1.10 & 0.00 & 0.01 & 0.01 & 0.01 & 48.89 & 0.46 & 0.03 \\
\hline NL- Netherlands & 0.14 & 0.08 & 0.14 & 0.01 & 0.33 & 0.00 & 0.02 & 0.03 & 0.01 & 0.00 & 59.27 & 0.16 \\
\hline NO- Norway & 0.06 & 0.02 & 0.06 & 0.20 & 0.22 & 0.00 & 0.13 & 0.00 & 0.04 & 0.01 & 0.35 & 62.43 \\
\hline PL- Poland & 0.22 & 0.05 & 1.32 & 0.07 & 0.94 & 0.00 & 0.03 & 0.01 & 0.01 & 0.00 & 0.57 & 0.42 \\
\hline PT- Portugal & 0.02 & 0.01 & 0.04 & 0.01 & 0.24 & 0.00 & 0.01 & 0.47 & 0.01 & 0.00 & 0.50 & 0.03 \\
\hline RO- Romania & 0.11 & 0.21 & 0.06 & 0.00 & 6.91 & 0.00 & 0.01 & 0.00 & 0.00 & 0.00 & 0.10 & 0.02 \\
\hline SE- Sweden & 0.25 & 0.07 & 0.12 & 0.12 & 0.25 & 0.00 & 0.06 & 0.01 & 0.05 & 0.02 & 0.30 & 1.58 \\
\hline SI- Slovenia & 0.01 & 0.03 & 0.05 & 0.00 & 0.76 & 0.01 & 0.00 & 0.00 & 0.00 & 0.00 & 0.19 & 0.01 \\
\hline SK- Slovakia & 0.13 & 0.56 & 0.24 & 0.01 & 0.61 & 0.00 & 0.01 & 0.01 & 0.01 & 0.00 & 0.32 & 0.12 \\
\hline UK- United Kingdom & 0.30 & 0.13 & 0.60 & 0.01 & 0.38 & 0.00 & 0.13 & 0.01 & 0.03 & 0.02 & 0.29 & 0.08 \\
\hline RW- Rest of World & 0.01 & 0.01 & 0.01 & 0.00 & 0.15 & 0.00 & 0.00 & 0.00 & 0.00 & 0.00 & 0.02 & 0.01 \\
\hline
\end{tabular}


Table A3: (Continued)

\begin{tabular}{|c|c|c|c|c|c|c|c|c|c|c|c|c|}
\hline Send & ing & & & & & & ceiving & Country & & & & \\
\hline Cour & try $i$ & PL & PT & RO & SE & SI & SK & UK & RW & $e_{0}^{i^{*}}$ & $e_{0}^{i i}$ & $\sum_{j} e_{0}^{i j} \quad(i \neq j)$ \\
\hline AT- & Austria & 0.73 & 0.11 & 1.05 & 0.13 & 0.23 & 0.65 & 0.68 & 12.05 & 75.79 & 52.19 & 23.59 \\
\hline BE- & Belgium & 0.32 & 0.11 & 0.06 & 0.15 & 0.03 & 0.07 & 1.30 & 7.24 & 76.35 & 58.79 & 17.56 \\
\hline BG- & Bulgaria & 0.21 & 0.05 & 0.49 & 0.06 & 0.00 & 0.38 & 1.06 & 10.14 & 72.81 & 49.29 & 23.52 \\
\hline $\mathrm{CH}-$ & Switzerland & 0.50 & 0.19 & 0.13 & 0.35 & 0.15 & 0.33 & 2.75 & 8.89 & 76.92 & 45.78 & 31.14 \\
\hline CY- & Cyprus & 0.21 & 0.02 & 1.25 & 0.18 & 0.02 & 0.07 & 5.05 & 35.07 & 73.10 & 21.60 & 51.50 \\
\hline CZ- & Czech Republic & 0.14 & 0.03 & 0.26 & 0.06 & 0.01 & 1.70 & 1.10 & 27.49 & 73.22 & 38.39 & 34.84 \\
\hline DE- & Germany & 2.04 & 0.18 & 0.37 & 0.18 & 0.04 & 0.18 & 0.98 & 6.27 & 76.53 & 61.01 & 15.52 \\
\hline DK- & Denmark & 0.31 & 0.07 & 0.06 & 3.87 & 0.01 & 0.14 & 1.49 & 7.97 & 75.97 & 55.46 & 20.51 \\
\hline EE- & Estonia & 0.08 & 0.02 & 0.03 & 1.10 & 0.00 & 0.04 & 2.53 & 8.63 & 72.91 & 49.88 & 23.03 \\
\hline ES- & Spain & 0.12 & 0.40 & 0.49 & 0.11 & 0.01 & 0.04 & 1.09 & 11.87 & 76.35 & 58.23 & 18.12 \\
\hline FI- & Finland & 0.09 & 0.02 & 0.01 & 2.08 & 0.00 & 0.05 & 0.59 & 2.46 & 76.81 & 67.31 & 9.50 \\
\hline FR- & France & 0.20 & 0.23 & 0.06 & 0.07 & 0.01 & 0.06 & 1.16 & 5.63 & 76.90 & 66.32 & 10.58 \\
\hline GR- & Greece & 0.32 & 0.02 & 0.15 & 0.20 & 0.00 & 0.05 & 1.32 & 4.70 & 77.04 & 66.32 & 10.72 \\
\hline $\mathrm{HU}-$ & Hungary & 0.15 & 0.04 & 0.44 & 0.15 & 0.01 & 0.57 & 0.99 & 8.60 & 72.93 & 55.26 & 17.67 \\
\hline IE- & Ireland & 0.98 & 0.12 & 0.13 & 0.21 & 0.00 & 0.07 & 3.90 & 9.90 & 76.06 & 54.29 & 21.77 \\
\hline IS- & Iceland & 1.20 & 0.22 & 0.04 & 4.29 & 0.01 & 0.18 & 3.85 & 8.28 & 76.73 & 41.45 & 35.27 \\
\hline IT- & Italy & 0.21 & 0.03 & 0.07 & 0.05 & 0.03 & 0.07 & 0.45 & 2.62 & 78.09 & 71.35 & 6.75 \\
\hline LI- & Liechtenstein & 0.58 & 0.02 & 0.06 & 0.02 & 0.01 & 0.21 & 0.14 & 8.77 & 76.95 & 55.64 & 21.30 \\
\hline LT- & Lithuania & 0.52 & 0.11 & 0.03 & 0.83 & 0.00 & 0.05 & 2.42 & 8.04 & 71.85 & 49.05 & 22.80 \\
\hline LU- & Luxembourg & 0.45 & 3.56 & 0.09 & 0.41 & 0.05 & 0.07 & 3.69 & 5.09 & 76.84 & 32.27 & 44.57 \\
\hline LV- & Latvia & 0.12 & 0.04 & 0.02 & 0.44 & 0.00 & 0.05 & 1.63 & 15.73 & 71.07 & 47.04 & 24.03 \\
\hline MT- & Malta & 0.08 & 0.04 & 0.02 & 0.14 & 0.02 & 0.10 & 3.98 & 17.13 & 75.49 & 48.89 & 26.60 \\
\hline NL- & Netherlands & 0.40 & 0.19 & 0.05 & 0.27 & 0.01 & 0.09 & 1.57 & 7.57 & 76.70 & 59.27 & 17.43 \\
\hline NO- & Norway & 0.41 & 0.05 & 0.05 & 3.05 & 0.00 & 0.17 & 1.44 & 4.21 & 77.36 & 62.43 & 14.93 \\
\hline PL- & Poland & 48.70 & 0.04 & 0.05 & 0.46 & 0.01 & 0.20 & 2.74 & 8.56 & 74.35 & 48.70 & 25.65 \\
\hline PT- & Portugal & 0.07 & 61.47 & 0.05 & 0.07 & 0.00 & 0.03 & 1.47 & 5.69 & 76.36 & 61.47 & 14.89 \\
\hline RO- & Romania & 0.08 & 0.06 & 46.14 & 0.05 & 0.00 & 0.53 & 0.29 & 8.59 & 73.42 & 46.14 & 27.28 \\
\hline SE- & Sweden & 0.49 & 0.06 & 0.03 & 62.03 & 0.02 & 0.08 & 1.40 & 5.32 & 77.45 & 62.03 & 15.42 \\
\hline SI- & Slovenia & 0.06 & 0.01 & 0.02 & 0.10 & 67.66 & 0.23 & 0.06 & 3.09 & 76.01 & 67.66 & 8.34 \\
\hline SK- & Slovakia & 0.21 & 0.05 & 0.15 & 0.09 & 0.02 & 42.72 & 2.27 & 12.01 & 73.92 & 42.72 & 31.20 \\
\hline UK- & United Kingdom & 0.27 & 0.11 & 0.04 & 0.18 & 0.01 & 0.07 & 60.26 & 9.16 & 76.02 & 60.26 & 15.75 \\
\hline RW- & Rest of World & 0.02 & 0.01 & 0.01 & 0.02 & 0.00 & 0.01 & 0.14 & 58.01 & 58.84 & 58.01 & 0.83 \\
\hline
\end{tabular}

Source: Authors' calculations

Notes: The expected duration of residence of international migration is a conditional life expectancy at age zero, defined as the average number of years that a person is expected to live in the receiving country $j$ above age zero given prior residence in * country $i$ at age zero (Willekens and Rogers 1978; see also Palloni 2001).

$e_{0}^{i *}=$ Total life expectancy above age zero in sending country $i$

$e_{0}^{i i}=$ Average number of years a person can expect to live beyond age zero in country $i$ given prior residence in country $i$ at exact age zero

$\sum_{j} e_{0}^{i j}(i \neq j)=$ Average number of years a person can expect to live beyond age zero in any country but $i$ given prior residence country $i$ at exact age zero $n$ 
DeWaard \& Raymer: The temporal dynamics of international migration in Europe 